This item was submitted to Loughborough's Research Repository by the author.

Items in Figshare are protected by copyright, with all rights reserved, unless otherwise indicated.

\title{
Friction and surface fracture of a silicon carbide ceramic brake disc tested against a steel pad
}

\section{PLEASE CITE THE PUBLISHED VERSION}

http://dx.doi.org/10.1016/j.jeurceramsoc.2015.07.009

\section{PUBLISHER}

(c) Elsevier

VERSION

AM (Accepted Manuscript)

\section{PUBLISHER STATEMENT}

This work is made available according to the conditions of the Creative Commons Attribution-NonCommercialNoDerivatives 4.0 International (CC BY-NC-ND 4.0) licence. Full details of this licence are available at: https://creativecommons.org/licenses/by-nc-nd/4.0/

\section{LICENCE}

CC BY-NC-ND 4.0

\section{REPOSITORY RECORD}

Bian, Guangyu, and Houzheng Wu. 2015. "Friction and Surface Fracture of a Silicon Carbide Ceramic Brake Disc Tested Against a Steel Pad”. figshare. https://hdl.handle.net/2134/18602. 


\title{
Friction and surface fracture of a silicon carbide ceramic brake disc tested against a steel pad
}

\author{
Guangyu Bian Houzheng Wu* \\ Department of Materials, Loughborough University, Leicestershire LE11 3TU, UK
}

\begin{abstract}
Friction coefficients of a SiC ceramic disc were measured on a laboratory-scale dynamometer by testing against a mild steel pad under different initial braking speeds, and its friction surface was investigated with microscopy techniques. At bedding, averaged friction coefficient for a braking stop varied significantly with the initial braking speed; after bedding, it converged to $\sim 0.6$, regardless of braking speed. Surface fracture on the $\mathrm{SiC}$ disc was responsible for the transformation from a flat surface into a rough one, making ploughing a dominant friction mechanism at bedded stage. It was found that fracture surface and non-contact regions directly contributed friction coefficient variation at bedding stage. Friction layer composed of iron oxides and plastic deformation with partial dislocations activated appeared on SiC surface, but were unsustainable owing to surface fracture. A quantitative analysis is provided to understand friction coefficient variation and SiC surface fracture during braking.
\end{abstract}

*Corresponding author, email: Tel.:+44 1509 223342; Fax: +44 1509 223949; E-mail Address: h.wu2@lboro.ac.uk (H.Wu) 
Key words: SiC; friction; surface fracture; contact; speed.

*Corresponding author, email: Tel.:+44 1509 223342; Fax: +44 1509 223949; E-mail Address: h.wu2@lboro.ac.uk (H.Wu) 


\section{Introduction}

Silicon carbide becomes a key constituent in a carbon fibre reinforced ceramic composite, a material that has been exploited actively as a new generation of brake disc, or rotor, for braking application in automotive vehicles, airplanes and heavy duty machineries ${ }^{1,2,3,4,5,6}$. Such application requires a friction couple capable of providing customer specified friction coefficient under various braking speeds and pressures across the lifetime of a brake ${ }^{7}$. To achieve such, most practiced strategy is to establish a sustainable friction surface on the contact regions by promoting the deposition of transferred materials ${ }^{8,9}$, through optimising the chemical composition of a friction material that includes reinforcement, abrasive, lubricant and filler that are bonded together by resin or metal ${ }^{10}$. Whilst such a strategy is proved very successful in tailoring or optimising the friction coefficient of a brake that consists of a cast iron rotor, recent research demonstrated that, for a brake consisting of SiC-based composite disc, it was difficult to develop a sustainable friction surface with a friction transfer layer successfully deposited ${ }^{11,12,13}$. Apart from lack of strong enough chemical bonding between transferred materials and silicon carbide substrate ${ }^{13}$, the fundamental issue is friction-induced cracking that occurs on surface of silicon carbide during braking ${ }^{12}$. Such cracking can wipe off any deposited friction transfer layer through chipping off on $\mathrm{SiC}$ surface, leading to a change of friction mechanism, making friction coefficient unstable.

Under a moving contact condition, a susceptibility to surface cracking of silicon carbide has drawn researchers' attention in tribological study for a long time ${ }^{14,15,16}$. The friction and wear 
of SiC ceramics exhibit strong dependency on testing load, sliding speed, configuration, counterpart materials, environment, and temperature; their impact on triological behaviour of SiC ceramics has been fairly reasonably established ${ }^{17,18}$. As a highlight, a silicon carbide ceramic can subject to a mild wear in the early stage of contact or under mild testing conditions; a plastically deformed surface is developed through surface smearing; and a friction transfer layer is deposited on if wear debris can have strong enough chemical bonding with silicon carbide, leaving a friction track showing smooth morphology, as observed by Andersson \& Holmberg ${ }^{19}$. Under a prolonged testing, or even severer testing conditions, e.g. high pressure/speed, surface cracking is likely introduced during contact sliding, as observed by $\mathrm{Gahr}^{20}$. One mechanism responsible for surface cracking under contact is established based on indentation fracture mechanics, indicating that harder abrasive debris, or asperities on surface of a counterpart, play a key role in initiating radial cracks ${ }^{14}$. Another mechanism is developed and accepted based on the surface tensile stress induced by a moving Hertzian contact and/or possibly thermal strain; such stresses drive pre-existing surface flaws propagation once the stress intensity is larger than the fracture toughness of a ceramic ${ }^{16}$. Quantitative correlations between surface tensile stress and some of contact conditions have been proposed and validated, but not yet for the rest - for instance, how the sliding speed influences the tensile stress level is not yet quantitatively established.

Despite a fact that sliding speed has a significant impact on the tribological behavior of a friction couple, most tribological studies are conducted on testing equipment, such as pin on 
disc, that can be operated inside a relatively lower speed regime (typically $<4 \mathrm{~m} / \mathrm{s})^{19}$, comparing to the possible maximum sliding speed used by brakes in automobile vehicles. For vehicle brake application, the typical sliding speed during braking can be as high as $>20 \mathrm{~m} / \mathrm{s}$, which leads to a situation that tribological knowledge in literature is not enough to fully cope the contact sliding conditions used by brakes for vehicles. For instance, the high speed may have significant impact on the friction performance through influencing the friction transfer layer deposition, surface deformation, and surface fracture. Based on such situation, it is therefore deemed necessary to conduct a fundamental study on how high sliding speed influences the friction performance of SiC-based friction couples. As steel is one of most important constituents in friction materials for pads, a mild steel is chosen as the complement part of a $\mathrm{SiC}$ ceramic for friction study. It is expected that outcomes from this study are helpful in understanding friction performance of SiC based composite brakes, as well as in optimizing the constituents of friction materials for pads suitable for ceramic composite brakes.

\section{Experimental procedures}

\subsection{Tested materials and manufacture of brake disc and pad}

A sintered $\alpha$-SiC ceramic (Morgan AM\&T, UK) was selected as a brake disc material, and a mild steel (grade EN10025/Fe430B/S275JR, Adey Steel Ltd., UK) a brake pad material. The SiC tiles were die-pressed and sintered in a vacuum furnace at a temperature of around 
$1900-2000{ }^{\circ} \mathrm{C}$, giving a density between $3.02-3.08 \mathrm{~g} / \mathrm{cm}^{3}$ and a residual porosity around 5\%. The averaged grain size, measured using intercept method, of the SiC ceramic is $\sim 5 \mu \mathrm{m}$, but some elongated grains are seen fairly frequently with a length larger than $50 \mu \mathrm{m}$. According to the suppliers' specification, the carbon content of the mild steel is $0.21 \mathrm{wt} \%$, and the maximum contents of other chemicals are: Mn 1.5wt\%, P $0.045 w t \%$, S $0.045 w t \%$. The average yield strength of this steel is about 260MPa.

The as-received SiC tiles were machined into brake discs with an outside diameter (OD) of $\sim 60 \mathrm{~mm}$ by directly boring through the thickness $(\sim 10 \mathrm{~mm})$ with a core drill coated with diamond grits. Two symmetrically distributed through holes, used for bolting a disc onto the testing rig, were bored with an inner diameter (ID) of $\sim 4 \mathrm{~mm}$ and a distance of $\sim 26 \mathrm{~mm}$ apart around the centre of a disc. The testing surface of each SiC disc was ground and polished on a Kemet 15 lapping machine (Kemet, UK) with diamond slurry. The grit size of diamond slurry for the final finish is $1 \mu \mathrm{m}$, giving a surface roughness, $\mathrm{Ra}$, of $0.03 \mu \mathrm{m}$ measured with a Mitutoyo SJ210 profilometer (Mitutoyo, UK).

All brake pads were prepared through the following procedures. Firstly, the as-procured steel rods were machined into discs with an OD of $50 \mathrm{~mm}$ and a thickness of $10 \mathrm{~mm}$. Further machining was then followed in order to form two $1 / 8^{\text {th }}$ arc lips with an ID of $38 \mathrm{~mm}$ at centrally symmetric positions along the disc rim. Finally, the surfaces of all lips were ground with 500 grade $\mathrm{SiC}$ sand papers, giving a Ra of 0.3-0.5 $\mu \mathrm{m}$. The drawings of the SiC disc and 
steel pad are shown in Figure 1.

\subsection{Friction testing}

The friction testing was conducted on a laboratory-scale dynamometer with an inertia of 4.70 $\mathrm{gm}^{2}$. Details on this testing rig are available in reference 12 . Testing conditions used in this study are summarised here. The as-machined brake disc and pad were installed on the testing rig with appropriate alignment, mainly relying on operator's judgement. Before contacted by the pad to start the execution of braking, the disc was spun to one of the following three speeds: 4000, 6500 and $9000 \mathrm{rpm}$, corresponding to a sliding speed of 8.5, 14.0, and $20.0 \mathrm{~m} / \mathrm{s}$, respectively, along a circular position of the effective radius of the friction track. A constant pressure of 2.1 MPa was applied on the pad throughout all braking operations. The interval between the end of previous braking and the start of the new one was fixed as 5 seconds, and the typical braking time required for each stop was in a range between 0.2 to 1.4 seconds, depending on the level of friction coefficient. For each test, 200 braking stops were accomplished in one go. The rotation speed, braking load, and braking torque are directly collected by a data logger with a capture frequency of $50 \mathrm{~Hz}$. The coefficient of friction was calculated using the following equation:

$$
\mu=\frac{T}{P_{0} \times S_{e} \times R_{e}}
$$

where $T$ is braking torque, $P_{0}$ braking pressure (2.1MPa here), $S_{e}$ is the friction contact area $\left(s_{e}=\frac{1}{8} \times \pi \times\left(50^{2}-38^{2}\right)=414.48 \mathrm{~mm}^{2}\right), \quad$ and $R e$ effective radius (22 mm here) of the 
friction contact track.

To investigate the variation of friction surface of a SiC disc with accumulated number of braking stops, braking test was intercepted after following accumulated number of stops: 1,4 , 8, 15, 50, 100 and 200. At each intercepting point, the as-braked disc and pad were taken off from the rig for microscopy analysis, before refitting them back to continue the braking test.

\subsection{Microscopy analysis of friction surface}

Friction surfaces were imaged by optical microscopy (MeF3, Reichert-Jung, Wien, Austria) under polarized and DIC lighting conditions. SEM/EDX (Leo 1530VP, Cambridge Instruments, Cambridge, UK) was used to identify the key chemical elements and microstructure on the friction surface. To examine the region underneath friction surface of SiC disc, cross-sections of a friction surface were made in a focused ion beam (FIB) microscope (FEI Nova 600, FEI, OR, USA), and electronic transparent foils were lifted for examination with transmission electron microscopy (TEM), JEOL-2000F (JEOL, Japan). Detailed procedures on preparing cross-section thin film samples with FIB have been highlighted in reference 13. All TEM/EDS analysis was operated under an accelerating tension of $200 \mathrm{kV}$. 


\section{Experimental results}

\subsection{Measurements of coefficient of friction}

The averaged coefficient of friction (CoF) measured for each braking stop is plotted against the number of accumulated braking stop under three initial braking speeds (IBSs), as shown in Figure 2. The averaged CoF converged to a level of $\sim 0.6$ after certain number of braking stops, indicating a bedded stage is achieved for a friction couple. Before reaching to the bedded stage, the variation of CoF followed its own pattern under each braking speed. Under $8.5 \mathrm{~m} / \mathrm{s}$, the CoF peaked with a level of $\sim 0.9$ at $6^{\text {th }}$ stop, followed by a steady fall to the converged level. Under $14 \mathrm{~m} / \mathrm{s}$, a small peak with a level of 0.64 appeared after just 2 stops, followed by a small fall to a lowest of $\sim 0.48$ at the $30^{\text {th }}$ stop, slightly lower than 0.52 that measured at the $1^{\text {st }}$ stop, and then a gradual rise to the converged level. Under $20 \mathrm{~m} / \mathrm{s}$, the CoF increased steadily from a level of $\sim 0.45$ measured at the first few stops to a maximum of $\sim 0.7$ at $65^{\text {th }}$ stop, followed by a gradual decline to the converged level. The observed friction performance will be correlated to the friction surface development in later sections.

\subsection{Friction surface development and characteristics on SiC disc}

The optical and scanning electron microscopy images of the friction surface of a SiC disc, subjected to different number of braking stops, are presented in Figures 3 and 4. Under an IBS of $8.5 \mathrm{~m} / \mathrm{s}$, debris from steel pad were sporadically deposited on the SiC surface after 4 braking stops, as shown in Figure 3 (b-c). Arrays of cracks crossing the friction track appeared randomly in the middle region of the friction track. These cracks presented in either 
a crescent, or straight line, as shown in Figure 3(b) and (c) respectively. Plastic deformation kinks were also noticed near the edges of the friction track (Figure 3(d)). The observation indicates that premature cracking and plastic deformation were initiated in the very early stage of braking. As the braking proceeded, fracture on surface became more obvious. After 35 braking stops, the friction surface is clearly divided into two parts: (a) the area attached with iron enriched friction transfer layer (FTL), which will be proved by TEM analysis below; and (b) the area that was subjected to fracture, as shown in Figure 3 (e). Such fracture characteristic became in dominant on the friction surface after 200 stops, as shown in Figure 3(f).

Under an IBS of $20 \mathrm{~m} / \mathrm{s}$, significant surface fracture happened even after the first braking stop, as shown in Figure 4(a). After 8 stops, more than 50\% of the friction track was chipped off; after 15 stops, the whole surface was chipped off, and appeared in dark contrast under optical imaging conditions due to scattering of the white light by a rough surface. SEM image of the friction surface after 1 stop revealed that transgranular fraction was in dominant on the fracture surface of the SiC, as shown in Figure 4(g-h). The terrace features along specific directions appearing on the fracture surface imply that cracking might have propagated along the crystal planes with atoms closely packed, as shown by Miyoshi \& Buckley ${ }^{14}$.

The deposition of transferred materials happened at the early stage of braking. These transferred materials either stock on the surface of SiC, or deposited inside pores, as shown in 
Figure 4(a), or Figure 3(e). SEM images of the friction surface, as shown in Figure 4(g-h), further support that the transferred materials were readily deposited (the light area) on the flat SiC. However, once the surface of SiC was fractured, very little deposition of the FTL was seen. The EDX spectrum showed that the deposited materials are composed of chemical element $\mathrm{O}, \mathrm{Si}, \mathrm{Fe}$ and $\mathrm{C}$.

\subsection{Cross-section of friction surface of SiC disc}

The cross-section of friction surface of SiC disc was analysed with TEM. The TEM samples were taken from a non-fractured area on the friction surface after 50 braking stops under an IBS of $8.5 \mathrm{~m} / \mathrm{s}$, and the cross-sectional structure is presented in Figure 5 . It shows that a friction transfer layer with a thickness of $\sim 0.2 \mu \mathrm{m}$ was deposited on top of SiC. The EDX spectra (Figure 5 (b)) demonstrate that the friction transfer layer is composed of $\mathrm{Fe}, \mathrm{O}$ and $\mathrm{Si}$, but no C. Note, the appearance of $\mathrm{Cu}$ peak in all spectra should be a contribution by copper grid used to hold the TEM sample. The atomic percentages of the chemical elements at position A, B and C are summarized below.

At position A near the top surface, the atomic ratio of Fe:Si:O is 25:16:58, proximately corresponding to a stoichiometry ratio of a combination of $\mathrm{SiO}_{2}+\mathrm{FeO}$, or $\mathrm{FeSiO}_{3}$. At position $\mathrm{B}$, around the middle of the transfer layer, the atomic ratio of Fe:Si:O ratio is $\sim 41: 16: 38$, which may correspond to substances as $\mathrm{SiO}_{2}+0.4 \mathrm{FeO}+2.2 \mathrm{Fe}$, or $0.4 \mathrm{FeSiO}+3.6 \mathrm{SiO}_{2}+2.2 \mathrm{Fe}$. At position C, Si is clearly enriched with an atomic ratio of Fe:Si:O of 4.5:32:63, suggesting a 
possible mixed constituents as $\mathrm{SiO}_{2}+0.14 \mathrm{Fe}$. Regions showing similar morphology as in position $\mathrm{C}$ are consistently presented on the interface near SiC substrate. Such fact implies that the bonding between $\mathrm{SiC}$ and Fe or iron oxides might have been realised through the formation of $\mathrm{SiO}_{2}$ phase first on the surface of $\mathrm{SiC}$.

Selected area diffraction pattern (Figure 5(a)) acquired from region around position A and B proved that the friction transfer layer was composed of crystallites, but some in small sizes. Estimated from the diffraction contrast images, the sizes are smaller than $50 \mathrm{~nm}$. By matching the ring pattern with the powder diffraction file (PDF) database, the nano-crystallites in position $\mathrm{B}$ is mainly composed of pure iron (PDF 1-1252) (indicated by the white rings) together with the presence of Wuestite iron oxide FeO (PDF 75-1550) phase (indicated by the red rings). Since no $\mathrm{Si}, \mathrm{Si}_{\mathrm{x}} \mathrm{Fe}_{\mathrm{y}}$ or silicon oxide crystals phase was identified in the friction transfer layer, the Si detected in region A and B is likely contributed by the amorphous Si-O regions near the interface. However, hard evidence for the existence of amorphous Si-O phase needs further characterization.

In the SiC side of the friction surface, TEM examination indicates the SiC grain was deformed with dislocations activated during braking. The bright field (BF) image in figure 6 (a) shows the overall microstructure of the cross section of the friction surface, including friction transfer layer above the $\mathrm{SiC}$ region and the $\mathrm{SiC}$ crystallite. The dark contrast in the SiC grain indicates a significant amount of lattice defects, which were likely activated by the 
friction baking operation.

By carefully tilting the sample, these crystal defects are displayed as partial dislocation arrays that were initiated from the top surface, followed by further gliding on the $\{0001\}$ basal planes and along the $<01 \overline{10}>$ direction to a deep position inside the SiC grains, as indicated in figure 6 (b-e). Note, the gliding of the partials follows the extension direction of the stacking faults (SFs) $<01-10>$ and is different from that of the perfect dislocations $<2 \overline{1} \overline{1} 0>$. Similar gliding behaviour of the partial dislocations was also observed in the $4 \mathrm{H} \mathrm{SiC}$ ceramics under electron radiation or indentation conditions ${ }^{21,22}$.

We have also conducted TEM analysis on the as manufactured SiC samples and the typical microstructure is shown in Figure 6 (f). It confirms that the as-manufactured $\mathrm{SiC}$ ceramics used in this study has almost no partial dislocations presented within the grains; if any stacking faults appear, they terminate at the grain boundaries. For SiC surface after braking, however, a large amount of partial dislocations were terminated within the grains. These dislocations located in a narrow region only (a strip shape in Figure 6 (a) and (c)), rather than homogenously distributed inside a grain. The cooperative slipping of the dislocations on the same basal plane are the key reason for the mechanical deformation kinks appeared on the SiC surface after four braking stops, as indicated in Figure 3. 


\section{Discussion}

By measuring averaged friction coefficient of each braking stop under different initial braking speeds and examining the friction surface of $\mathrm{SiC}$ disc, including its subsurface microstructure, the following points are generalised when a rotating $\mathrm{SiC}$ disc was decelerated by a mild steel pad:

(a) Averaged friction coefficient for a braking stop ultimately converged to a similar stable level, around 0.6 for all tests under three IBSs as braking stop number increases; on the other hand, the measurement in the early stage of each test demonstrated significant variance under each IBS, and among the three IBSs as well.

(b) Post-braking surface examination showed that transferred materials, typically composed of iron oxide crystallites bonded by Si-O phase, were deposited on flat SiC surface from the start of braking. However, such transferred materials hardly sustained on a fractured surface.

(c) Mechanical deformation, linking to the activation of subsurface partial dislocations, on flat contact regions and premature surface cracking were initiated in the early stage of braking. As testing proceeded, surface cracking progressively extended across the whole friction surface. The higher the initial braking speed was, the faster did the surface cracking extend.

Based on the experimental observation, we provide further analysis below on how friction coefficient for each braking stop and damage on surface of $\mathrm{SiC}$ disc were governed during braking. 


\subsection{Correlation between friction coefficient and accumulated braking stop number}

Considering a mild steel pad maintained its compliance without surface chipping/cracking, we accordingly infer that surface cracking on SiC disc ultimately dictated the level of friction for a brake consisting of a $\mathrm{SiC}$ brake and a mild steel pad. At this stage, the friction couple is operated in stable friction, or bedded friction; and the contact configuration of the friction surface between the disc and pad is schematically shown in Figure 7(d), where the whole surface of $\mathrm{SiC}$ is transformed from an as-polished one to a fractured one, giving a rough contour on the cross section. We call such contact a fracture surface contact hereafter. Since the hardness of $\mathrm{SiC}$ is much larger than either steel or any iron oxides as a film on friction surface, the SiC fracture surface provides enough asperities to plough the counterpart, hence called ploughing surface also. For a ploughing friction, the dynamic coefficient of friction, $\mu_{p l o}$, has been given by Bowden and Tabor $^{23}$ as eq. (2), based on a friction model consisting of a perfect conical tip to imitate any asperities that exist on the surface of one component made from relatively harder material.

$$
\mu_{p l o}=\frac{2 \cot \theta}{\pi}
$$

where $\theta$ is the half angle of the conic tip of an asperity. For a measured stable friction coefficient of $\sim 0.6$, eq.(2) gives an estimated average $2 \theta$ of $\sim 93.4^{\circ}$, which should be a reasonable estimation for a fracture surface showing terrace features as a consequence of 
cleavage along crystal planes with high density of atoms, as experimentally demonstrated by Miyoshi \& Buckley ${ }^{14}$. The total ploughing force applied on a fracture surface contact region should be

$$
F_{\text {plo }}=N_{\text {plo }} \mu_{\text {plo }}=S_{\text {plo }} P_{0} \mu_{\text {plo }}
$$

where $S_{\text {plo }}, N_{\text {plo }}, P_{0}$ are the area of a fracture surface contact, and normal force and pressure applied on it, respectively.

Before reaching to the stable friction, there should be another type of friction surface contact, where the SiC surface is flat with a layer of iron oxides deposited on the top, as shown in Figures 3-5. We call such contact a flat surface contact hereafter, and it gives adhesion friction only, if any ploughing by minor asperities is ignored. For the very initial contact of a test, flat surface contact should be the only one, as schematically shown in Figure 7(a); at the same time, non-contact regions likely exist, as highlighted in the schematics, primarily owing to any possible geometric misalignment because of a dome shape of a finished surface, and/or a non-parallel set up of the two friction surfaces before testing. As braking proceeds, noncontact region reduces gradually through self-alignment of the friction couple; flat surface contact is gradually damaged through cracking, and replaced by a fracture surface contact, as experimentally shown in Figures 3-4. This contact situation and progress are schematically shown in Figure 7(b) and (c). At certain stage after starting the braking test, the friction 
surface of SiC becomes a mixture of flat surface contact regions deposited with transferred materials and fracture surface contact ones developed through surface fracture. One can conclude that adhesion and ploughing must both govern the friction with a weight depending on the degree of surface fracture, which can be quantified as shown below.

For adhesion friction, the dynamic friction coefficient, $\mu_{a d h}$, can be expressed as

$$
\mu_{a d h}=\frac{\tau}{N_{a d h}}
$$

The friction force applied on a flat surface should be the shear strength of a contact region, $\tau$

$$
F_{a d h}=\tau=N_{a d h} \mu_{a d h}=S_{a d h} P_{a d h} \mu_{a d h}
$$

Where $S_{\text {adh }}$ and $N_{a d h}$ are the area of the contact region, and normal force applied on it, respectively. For a flat surface contact region, the friction surface of mild steel pad is oxidised fairly easily in the air environment, owing to a fact that the friction can introduce a surface temperature high enough for oxygen in air to react with iron element in steel ${ }^{9}$. Equally, any iron debris deposited on the SiC surface should subject to similar oxidation, and a similar iron oxide layer is therefore formed on SiC surface, as approved by the cross section TEM image shown in Figure 5. Therefore, the contact between the steel pad and a SiC region with transferred ferrous materials deposited should be a closer match of a friction couple consisting 
of two steel components under similar braking conditions. Lim \& Ashby $^{24}$ summarised the friction coefficient of steel versus steel under various sliding speeds, varying between 0.2 and 1.4 as speed increases. On the basis that all of our testing was in a high speed region, we choose the upper level, 1.4, for the $u_{a d h}$ in eq.(5).

The total friction force for each braking stop should therefore follow a mixture rule, weighted by the area of flat surface contact, $S_{a d h}$, and fracture surface contact, $S_{\text {fra }}$, and noncontact surface, $S_{\text {non }}$.

$$
F=S_{a d h} F_{a d h}+S_{f r a} F_{f r a}+S_{n o n} F_{n o n}=S_{a d h} P_{a d h} \mu_{a d h}+S_{f r a} P_{f r a} \mu_{f r a}+S_{\text {non }} \times 0
$$

Both sides in eq.(6) are divided by the braking normal force $\mathrm{N}=\mathrm{P}_{0} \mathrm{~S}$, and the friction coefficient should have the following format:

$$
\mu=\frac{F}{N}=\frac{S_{a d h} P_{a d h} \mu_{a d h}+S_{p l o} P_{p l o} \mu_{p l o}}{P_{0} S}
$$

where $S$ is the area of nominal contact area. The averaged pressure in the both flat surface contact and fracture surface contact should be the same as long as the mild steel pad provides enough compliance to cope the surface topography on SiC disc, i.e. $P_{a d h}=P_{\text {plo }}=P_{0}$. By setting $f_{a d h}=S_{a d h} / S$ and $f_{\text {plo }}=S_{p l d}$, the fraction of flat surface contact and fracture surface 
contact, respectively, Eq.(7) can be rewritten in following format:

$$
\mu=f_{\text {adh }} \mu_{\text {adh }}+f_{\text {plo }} \mu_{\text {plo }}
$$

Having friction coefficient in eq. (8) replaced by the estimated values for plough friction and adhesion friction, we have the following equation governing the friction performance of the brake before stable friction is achieved:

$$
\mu=1.4 f_{\text {adh }}+0.6 f_{\text {plo }}
$$

Note, the sum of $f_{\text {adh }}$ and $f_{\text {plo }}$ may be less than 1 due to the existence of non-contact regions, $\mathrm{f}_{\text {non }}$, i.e.

$$
f_{\text {adh }}+f_{\text {plo }}+f_{\text {non }}=1
$$

In order to link the friction coefficient to the braking stop number, $N$, we assume $f_{\text {plo }}$ and $f_{\text {non }}$ followed a power law with braking stop numbers, with an asymptote of 1 and 0 , respectively:

$$
\begin{aligned}
& f_{\text {plo }}=1-\frac{1}{N^{m}} \\
& f_{\text {non }}=\frac{b}{N^{k}}
\end{aligned}
$$


where $m$ and $k$ are powers to determine the variation rate of fracture surface contact and noncontact regions with the braking stop number; $b$ is the fraction of initial non-contact regions, which should be less than 1 . Eq. (9) can therefore be re-written to correlate to the braking stop number:

$$
\mu=0.6+\frac{0.8}{N^{m}}-\frac{1.4 b}{N^{k}}
$$

By using least square fitting method, friction coefficient data shown in Figure 2 can give $b, m$ and $k$ values under each initial braking speed, as summarised in table 1 . The fitting lines are shown in Figure 8(a), and the trend for each test is fitted with a reasonable confidence. From the values of $m, k$ and $\mathrm{b}$, we can draw following conclusions:

(a) With the increase of initial braking speed, the $m$ value increases. For instance, the $m$ vale under $20 \mathrm{~m} / \mathrm{s}$ is about 2.5 times that under $8.5 \mathrm{~m} / \mathrm{s}$, meaning that speed of surface fracture under $20 \mathrm{~m} / \mathrm{s}$ on $\mathrm{SiC}$ disc is about 2.5 times that under $8.5 \mathrm{~m} / \mathrm{s}$. Such difference aligns well to the observation of the degree of fracture damage appearing on friction surface shown in Figure 3 and 4.

(b) The values of $k$ and $b$ show no clear trend with the variation of initial braking speed. We believe this should be the case if the non-contact area is largely dictated by the non-parallel set up of the friction surfaces on disc and pad, which was based on the visual judgement of the operator. The variation can be fairly random from one test to 
another.

Therefore, the characteristic variation of friction coefficient in the early stage of friction testing, shown in Figure 2, may not represent the inherent friction performance of a friction couple, but tend to reflect the variation of non-contact regions. If we assume the non-contact region was 0 , i.e. the friction surface had been in full contact from the beginning of the braking test, the measurement of friction coefficient should have followed a power law correlation with the braking stop number as following:

$$
\mu=0.6+\frac{0.8}{N^{m}}
$$

If $m$ values are the same as shown in table 1 , higher value of $m$ under high initial braking speed means faster bedding through accelerated surface fracture, as shown in Figure 8(b).

\subsection{Friction-induced fracture on surface of SiC disc}

Friction data analysis shows that surface fracture of the SiC disc has a strong influence on the variation of friction coefficient as braking operation proceeds, which is reflected by eqs. (13) and (14). Through microstructural examination of post-braking surface of the disc, the surface fracture might have been associated with the following phenomena observed: (a) Premature cracks that appeared in the early stage of braking in a crescent or straight line with a length around 40-50 $\mu \mathrm{m}$; (b) dislocations that were activated on SiC surface of regions that have flat 
surface contact with steel pad. First, we use fracture mechanics to analyse the premature cracking on friction surface.

The contact between the steel pad and the disc belongs to a sliding non-Hertzian normal contact of elastic bodies. As an approximation for the convenience of quantitative analysis, we simplify the contact as a cylindrical slider moves perpendicular to its axis over a flat surface with a steady velocity of $V$, as used by Johnson ${ }^{25}$. Under such a contact configuration, the stresses and deformation due to normal pressure, $P_{0}$, and friction contraction, $q_{0}$, can be treated independently; a further assumption is made that the impact of different elasticity between steel pad and $\mathrm{SiC}$ disc is negligible, which is reasonable according to Johnson's estimation $^{25}$.

Under a normal pressure, $p_{0}$, an equal compressive stress is applied on the surface and no stress is expected on the edge of contact and outside. For a friction stress, $q_{0}$, the surface stress is given by the following equations [2]:

$$
\begin{aligned}
\left(\bar{\sigma}_{x}\right)_{q}= & -2 q_{0} x / a & \text { when }|x| \leq a \\
& -2 q_{0}\left\{\frac{x}{a} \mp\left(\frac{x^{2}}{a^{2}}-1\right)^{\frac{1}{2}}\right\} & \text { when }|x|>a
\end{aligned}
$$

Where $a$ is the half width of a contact, and $x$ the distance away from the central point of the contact. Eq.(15) shows that inside the contact, the surface stress is a compression with a 
maximum of $2 q_{0}$; the leading edge of the contact $(x=a)$ has a maximum compression of $-2 q_{0}$, and at the trailing edge $(x=-a)$ there exists a maximum tension of $2 q_{0}$. It should be note here that the surface tensile estimated by eq. (15) has very limited difference, comparing to that estimated by eq. (2) in ref. 16.

To initiate cracking in SiC, a fracture criterion must be met. We assume that the surface stress is approximately uniform in magnitude, and extends to a depth greater than pre-existing surface crack, $c_{0}$, the critical condition for surface cracking to be initiated is approximated as

$$
K_{I} \geq 1.12\left(\bar{\sigma}_{x}\right)_{q} \sqrt{\pi c_{0}}=2.24 q_{0} \sqrt{\pi c_{0}}=2.24 \mu p_{0} \sqrt{\pi c_{0}}
$$

In eq.(16), the values for the following parameters are available: fracture toughness $\mathrm{K}_{\mathrm{IC}}$ for the tested $\mathrm{SiC}$ is $3.0 \mathrm{MPa} \cdot \mathrm{m}^{1 / 2}{ }^{26}$; friction coefficient for a flat surface contact is 1.4 . The nominal pressure, $\mathrm{P}_{0}$, of braking is $2.1 \mathrm{MPa}$, but the real pressure applied on a flat contact region is determined by the fraction of contact out of the nominal friction area, $f$, i.e. $p_{0}=P_{0} / f$. Having parameters in eq.(16) replaced by the values above, we have the surface cracking criterion achieved by correlating pre-existing surface flaw size to the fraction of real contact:

$$
c_{0} \geq 66088 f^{2}(\mu \mathrm{m})
$$

Recent measurement of flaw population on the as-polished surface of the same SiC ceramics 
showed that the possible maximum flaw size is about $20-40 \mu \mathrm{m}^{26}$, giving a fraction of contact regions less than $\sim 2.5 \%$, if cracking is initiated from these large flaws. When the fraction of real contact region is as small as $1 \%$, the critical surface flaw size that surface cracking can be initiated is $6.6 \mu \mathrm{m}$. Note flaws with size larger than $6.6 \mu \mathrm{m}$ is highly populated on a polished surface (flaw population details are available in ref. 26).

Quantitative analysis above has shown that surface fracture is likely initiated when the friction surface has a small amount of real contact between pad and disc. As the real contact extends, the initiation of surface cracking is expected to be held at some stage. Such a small fraction of real contact is possible only when the contact is in the very initial stage of each braking operation, and likely defined by factors such as the surface topography of friction surfaces, parallel alignment of the set-up, and vibration of the testing rig. Therefore, considering the contacting process, it is reasonable if we assume that the extending rate of real contact regions is independent of the initial braking speed (or the rotor's speed before braking is applied), at least in a short period of time after the start of initial contact. We assume the time required for the initial contact fraction increases from $0 \%$ to $2.5 \%$ is fixed as $t_{0}$ under all conditions, and the number of circles, $n$, that the disc rotates inside this period is

$$
n=t_{0} V \text { (cycles) }
$$

By increasing the initial braking speed, the number of rotating cycle increases proportionally. 
Assume that number of cracks initiated by each cycle is the same, and the total number of cracks, $\sum c_{0}$, inside the period of $t_{0}$ should be proportional to the initial braking speed, i.e.

$$
\sum c_{0}=\alpha V
$$

Where $\alpha$ is a constant independent of IBS. Surface cracking leads to surface chipping through either liaison of initiated surface cracks or lateral cracking, which converts the as-finished flat surface into rough fracture surface. Therefore, the observed area, or fraction $\left(f_{\text {plo }}\right)$, of fracture surface on a friction surface should be proportion to the total number of cracks initiated on the surface, i.e.

$$
f_{p l o}=\beta \sum c_{0}=\alpha \beta V
$$

Where $\beta$ is a constant.

To validate this surface fracture modelling, we need to test if the fraction of fracture surface on a friction surface is proportional to the initial braking speed. Based on the fitting value of m listed in table 1 , we have estimated the fraction of fracture surface generated by each braking stop from number 1 to 20 by using eq. (11) and their ratios among different initial braking speed, as shown in table 2, which can be summarised as follows: 


$$
\begin{aligned}
& \left(f_{p l o}\right)_{8.8 \mathrm{~m} / \mathrm{s}}:\left(f_{p l o}\right)_{14 \mathrm{~m} / \mathrm{s}}:\left(f_{p l o}\right)_{20 \mathrm{~m} / \mathrm{s}}=1:(1.32 \sim 1.41):(2.16 \sim 2.95) \\
& (V)_{8.8 \mathrm{~m} / \mathrm{s}}:(V)_{14 \mathrm{~m} / \mathrm{s}}:(V)_{20 \mathrm{~m} / \mathrm{s}}=1: 1.65: 2.35
\end{aligned}
$$

As a first approximation, the fraction ratio of fracture surface developed by each braking test is very close to the ratio of the initial braking speed. Such agreement means that relationship in eq.(20) is valid and the surface fracture is likely controlled by the small amount of real contact at the very initial stage of braking.

The onset of plastic yield in sliding contact will be governed by the maximum value of the principal shear stress throughout the field. In the absence of friction, the maximum shear stress is $0.3 \mathrm{P}_{0}$ on the Z-Axis at a depth 0.78 a for a typical Hertzian contact. Having the tangential traction accounted, the maximum value shifts at a point closer to the surface, but not necessarily on the surface. However, the observed dislocations are on the top surface with an extension to a depth of $\sim 5 \mu \mathrm{m}$ only; therefore, it is hard to justify that the shear stress generated by the normal and tangent force on the friction interface contributed the development of these dislocation. In fact, these dislocations are more likely develop as those generated through an abrasion process in other ceramics ${ }^{27,28}$

On the other hand, plastic deformation could become another mechanism of surface cracking damage, through piling up of dislocations due to constrained mobility of the front of a slip 
and/or the interaction among the slips, where when a tensile is high enough, microcracking can be initiated. However, an intensive interaction among the slips was not observed in this study, as shown in Figure 6, so was constrained slips. Therefore, we believe that the formation of dislocations on the surface of $\mathrm{SiC}$ might have had a minor impact on the observed surface fracture if there was any.

Friction does generate heat on the contact regions, which could be heated up locally to high temperature and cooled down suddenly when they are not in contact. Such thermal shock can lead to fracture damage, as analysed in details in reference 16 . However, we did not see cracking patterns, typically circular crack, or meshed crack, on the friction surface that could be attributed to thermal shock. Therefore, we do not believe thermal shock would be the primary reason for surface fracture of SiC disc.

\section{Summary}

We have studied the friction behaviour of a brake consisting of a SiC ceramic disc and a steel pad under simulated automotive braking conditions with three different initial braking speeds, $8.5 \mathrm{~m} / \mathrm{s}, 14 \mathrm{~m} / \mathrm{s}$ and $20 \mathrm{~m} / \mathrm{s}$. For all three speeds, the averaged friction coefficient for each braking stop converged to a same level, $\sim 0.6$, after the bedding. The variation of average friction coefficient at bedding stage follows different patterns among the tests under different initial braking speeds. Quantitative analysis shows the variation pattern is dictated by the 
fraction of non-contact regions and the speed of friction-induced surface fracture on SiC disc.

Experimental evidences show that the stable friction after bedding is fully dictated by the ploughing as a consequence of surface fracture of SiC disc. Fracture mechanics analysis demonstrates that such surface fracture is likely introduced during the initial period of each braking contact when a high enough surface tensile at the trail end of the moving contact gives a stress intensity larger than fracture toughness of SiC. Modelling shows that higher initial braking speed provides more surface cracking due to more repeated contacts are provided inside a short period of initial contact, leading to a faster surface cracking than under a lower initial braking speed.

Friction transfer layer composed of iron oxide crystallites was firmly bonded on surface of SiC, but after surface fracture, almost no transferred materials were deposited on friction surface. Plastic deformation appeared on SiC surface through activating dislocations, but it is believed such plastic deformation has little contribution to the surface fracture.

\section{Acknowledgment}

We are very grateful to the Technology Strategy Broad (TSB), UK for providing financial support for this research, and a number of industry partners for providing support and helpful discussion. GB would also like to gratefully acknowledge Loughborough University for 
providing additional financial support for his $\mathrm{PhD}$ study.

\section{Reference}

${ }^{1}$ P. Blau, Compositions, functions, and testing of friction brake materials and their additives, Oak Ridge National Laboratory, ORNL/TM-2001/64, 2001.

${ }^{2}$ W. Krenkel, B. Heidenreich, and R. Renz, C/C-SiC composites for advanced friction application, Adv. Eng. Mater., 4 (2002) 427-436.

${ }^{3}$ P. Blau, Research on non-traditional materials for friction surfaces in heavy vehicle disc brakes, Ork Ridge National laboratory Report, ORNL/TM-2004/265, 2004.

${ }^{4}$ S. Vaidyaraman, M. Purdy, T. Walker \& S. Horst. C/SiC material evaluation for aircraft brake applications. In: Fourth International Conference on High Temperature Ceramic Matrix Composites (HT-CMC4) Proceedings. Munich, Germany, 2001. p.802-8.

${ }^{5}$ W. Krenkel \& F. Berndt, C/C-SiC composites for space applications and advanced friction system, Mater. Sci \& Eng. A412 (2005) 177-81.

${ }^{6}$ S. Fan, L. Zhang, Y. Xu, L. Cheng, G. Tian, S. K, F. Xu \& H. Liu, Microstructure and tribological properties of advanced carbon/silicon carbide aircraft brake materials, Comp. Sci \& Tech., 68 (2008) 3002-9

${ }^{7}$ T.W. Birch, Automotive brake systems, $2^{\text {nd }}$ edition, Fort Worth: Saunders College Pub, 1995.

${ }^{8}$ A. Wirth, D. Eggleston \& R. Whitaker, A fundamental tribochemical study of the third body layer formed during automotive friction braking, Wear, 179 (1994) 75-81.

${ }^{9}$ W. Osterle \& I Urban, Third body formation on brake pads and rotors, Trib. Inter., 39 (2006) 401-8.

${ }^{10}$ D. Chan \& G.W. Stachowiak, Review of automotive brake friction materials, Proc. Instn. Mech. Engrs. Part D: J. Automobile Engineering, 218 (2004) 953-66.

${ }^{11}$ Z. Stadler, K. Krnel \& T. Kosmac, Friction behaviour of sintered metallic brake pads on a C/C-SiC composite brake disc. J. Eu. Ceram. Soc. 27(2007) 1411-1417.

${ }^{12}$ Y. Wang \& H. Wu, Friction surface evolution of carbon fibre reinforced carbon/silicon carbide (Cf/C-SiC) composites, J. Eu. Ceram. Soc. 30 (2010) 3187-201.

${ }^{13} \mathrm{Y}$. Wang \& H. Wu, Microstructure of friction surface developed on carbon fibre reinforced carbon-silicon carbide (Cf/C-SiC), J. Eu. Ceram. Soc. 32 (2012) 3509-19.

${ }^{14}$ K. Miyoshi \& D.H. Buckley, Friction and wear behaviour of single-crystal silicon carbide in sliding contact with various metals, ASLE Trans. 22 (1979), 245-56.

${ }^{15}$ D.C. Cranmer, Friction and wear properties of monolithic silicon-based ceramics, J. Mat. Sci. 20 (1985) 2029-37.

${ }^{16}$ K. Adachi, K. Kato \& N. Chen, Wear map of ceramics, Wear 203-4 (1997) 291-301.

${ }^{17}$ X. Dong, S. Jahanmir \& L.K. Ives, Wear transition diagram for silicon carbide, Wear 28(1995) 559-72.

${ }^{18}$ S-J Cho, C-D Um \& S-S Kim, Wear and wear transition mechanism in silicon carbide during sliding, J. Am. Ceram. Soc., 78 (1995) 1076-8.

${ }^{19}$ P. Andersson, \& K. Holmberg, Limitations on the use of ceramics in unlubricated sliding applications due to transfer layer formation, Wear, 175 (1993) 1-8. 
${ }^{20}$ K.H.Z. Gahr, Sliding wear of ceramic-ceramic, ceramic-steel and steel-steel Pairs in lubricated and unlubricated contact, Wear, 133 (1989) 1-22.

${ }^{21}$ Y. Ohno, I. Yonenga, K. Miyao, K. Maeda \& H. Tsuchida, In-situ transmission electron microscopy of partial-dislocation glide in 4H-SiC under electron radiation. App. Phy. Lett., 101 (2012) 042102.

${ }^{22}$ K. Maeda, K. Suzuki, S. Fujita, M. Ichihara \& S. Hyodo, Defects in plastically deformed 6H SiC single crystals studied by transmission electron microscopy, Phil. Mag. A, 57 (1988) 573-592.

${ }^{23}$ F.P.Bowden \& D.Tabor, The Friction and Lubrication of Solids. Vol. Part 1. 1954, Oxford: Oxford University Press.

${ }^{24}$ S.C. Lim \& M.F. Ashby, Wear-mechanism maps, Acta Metall., 35 (1987) 1-24.

${ }^{25}$ K.L. Johnson, Contact Mechanics, Cambridge University Press, 1985 Ch. 7.

${ }^{26}$ J. Wade, S. Ghosh, P. Claydon \& H. Wu, Contact damage of silicon carbide ceramics with different grain structures measured by Hertzian and Vickers indentation, J. Eu. Ceram. Soc. 35(2015) 1725-36.

${ }^{27}$ R. Stevens, Defects in silicon carbide. J. Mat. Sci. 7 (1972) 517-521.

${ }^{28}$ H.Z. Wu, S.G. Roberts, G. Mobus \& B.J. Inkson, Subsurface damage analysis by TEM and 3D FIB mapping in alumina and alumina/5vol\% SiC nanocomposites, Acta Mater. 51 (2003) 149-163. 


\section{Figure \& table captions}

Figure 1 Drawings of SiC brake disc (a) and steel pad (b).

Figure 2 Measurements of averaged friction coefficient for each braking stop of a test that a SiC disc was braked by a steel pad under an initial braking speed of 8,14 and $20 \mathrm{~m} / \mathrm{s}$.

Figure 3 Representative optical microscopy images of SiC friction surface tested under a braking speed of $8.5 \mathrm{~m} / \mathrm{s}$. (a) as-polished surface; (b-c) after 4 braking stops when crescent cracks, straight cracks and deformation kinks appeared; (e) after 35 braking stops; (f) after 200 braking stops.

Figure 4 Representative optical microscopy (a-f) and SEM (g-h) images of SiC friction surface after braking under an initial braking speed of $20 \mathrm{~m} / \mathrm{s}$. (a) after 1 braking stop; (b) after 3 braking stops; (c) after 8 braking stops; (d) after 15 braking stops; (e) after 50 braking stops; (f) after 200 braking stops; (g-h) SEM images of the friction surface after 1 braking stop.

Figure 5 TEM images of a cross section of SiC friction surface after 50 braking stops under an initial braking speed of $8.5 \mathrm{~m} / \mathrm{s}$. (a) diffraction contrast image, including a representative selecting area diffraction pattern from A and B regions, shown as an inset; (b) representative EDX spectra showing the chemical composition in region $\mathrm{A}, \mathrm{B}$ and $\mathrm{C}$, respectively.

Figure 6 Friction induced lattice defects in $\mathrm{SiC}$ grains underneath the friction transfer layer. (a) Diffraction contrast image showing the overview of a cross-section, where region A and B were heavily deformed. The defects were initiated from region A near the surface and followed by further slippage to region B inside the grain. (b) High magnification BF image acquired from region A, showing a serial of dislocations initiated from the contact surface and started to glide deeply inside the grain; electron beam was parallel to $\{0001\}$ zone axis. (c) High magnification BF image acquired from region B, showing the defects were constrained in a narrow region; electron beam was tiled away from the $\{0001\}$ zone axis. (de) Double beam BF images acquired from region B, confirming these defects are composed of partial dislocations with high mobility and the associated stacking faults (note the dislocations in $\mathrm{A}$ is also the partial type). (f) $\mathrm{BF}$ image of the microstructure of asmanufactured SiC.

Figure 7 Schematic of the contact friction interface between a SiC disc and a steel pad at different stage of the friction test. (a) The initial contact showing noncontact regions (Snon) and flat contact regions (Sadh). (b) The early stage contact showing noncontact regions, flat contact regions, and contact regions consisting of fracture surface in SiC (Splo). (c) The middle stage contact showing flat contact regions and contact regions consisting of fracture surface in SiC. (d) The stable stage showing one type of contact consisting of surface fracture in SiC. S represents the area of each type of region and P0 the braking pressure.

Figure 8 (a) The trend of averaged friction coefficient varies with the accumulated braking stops predicted by eq. (13), derived from a friction model that consists of fracture surface contact, flat surface contact and non-contact. The trend was fitted by using least square method. (b) The estimated variation of fiction coefficient with braking stop number when the friction components are in complete contact during testing, as predicted by eq. (14). 
Table 1 Summary of values of $\mathrm{m}, \mathrm{k}$ and a included in eq. (13) under different braking initial speed.

Table 2 Estimated fraction of fracture surface generated by each braking stop and the ratios among braking under different initial braking speed. 


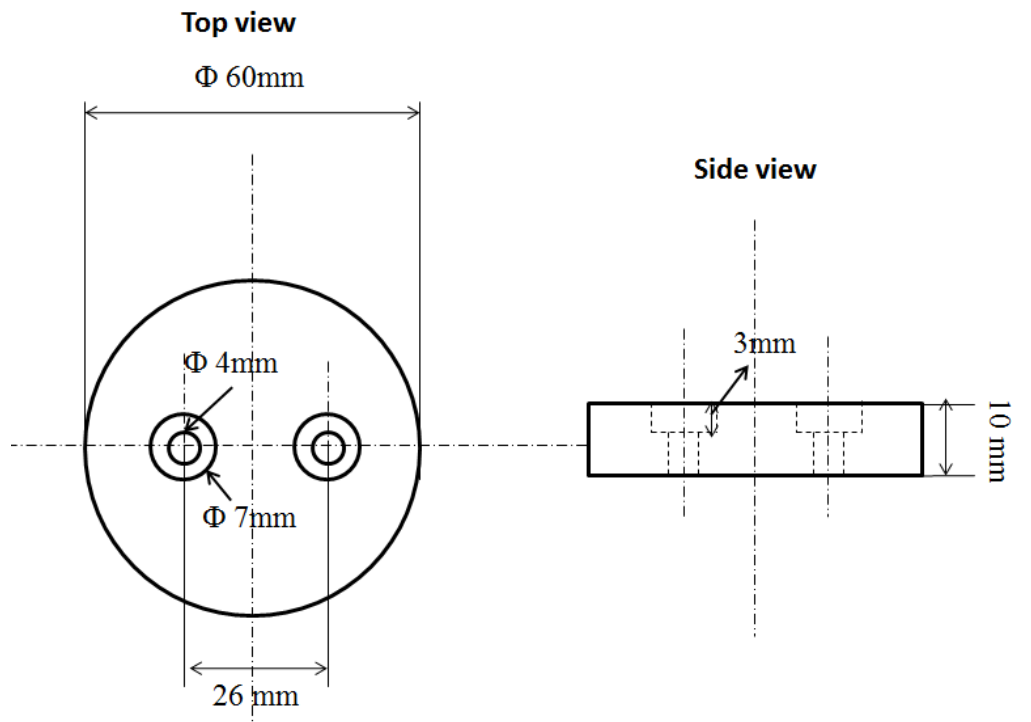

(a)
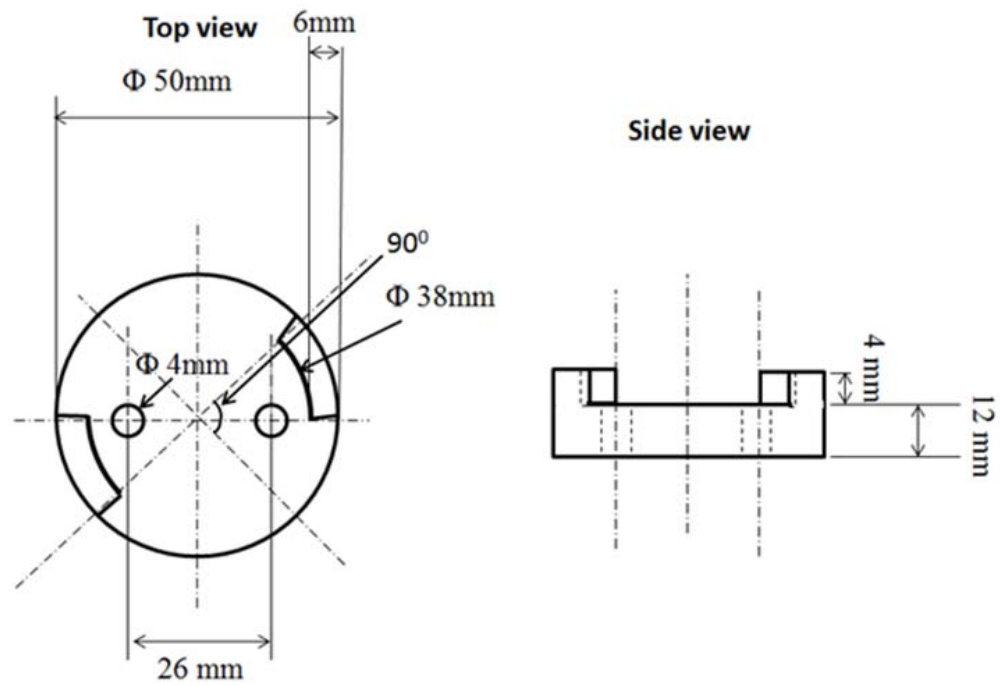

(b)

Figure 1 Drawings of SiC brake disc (a) and steel pad (b). 


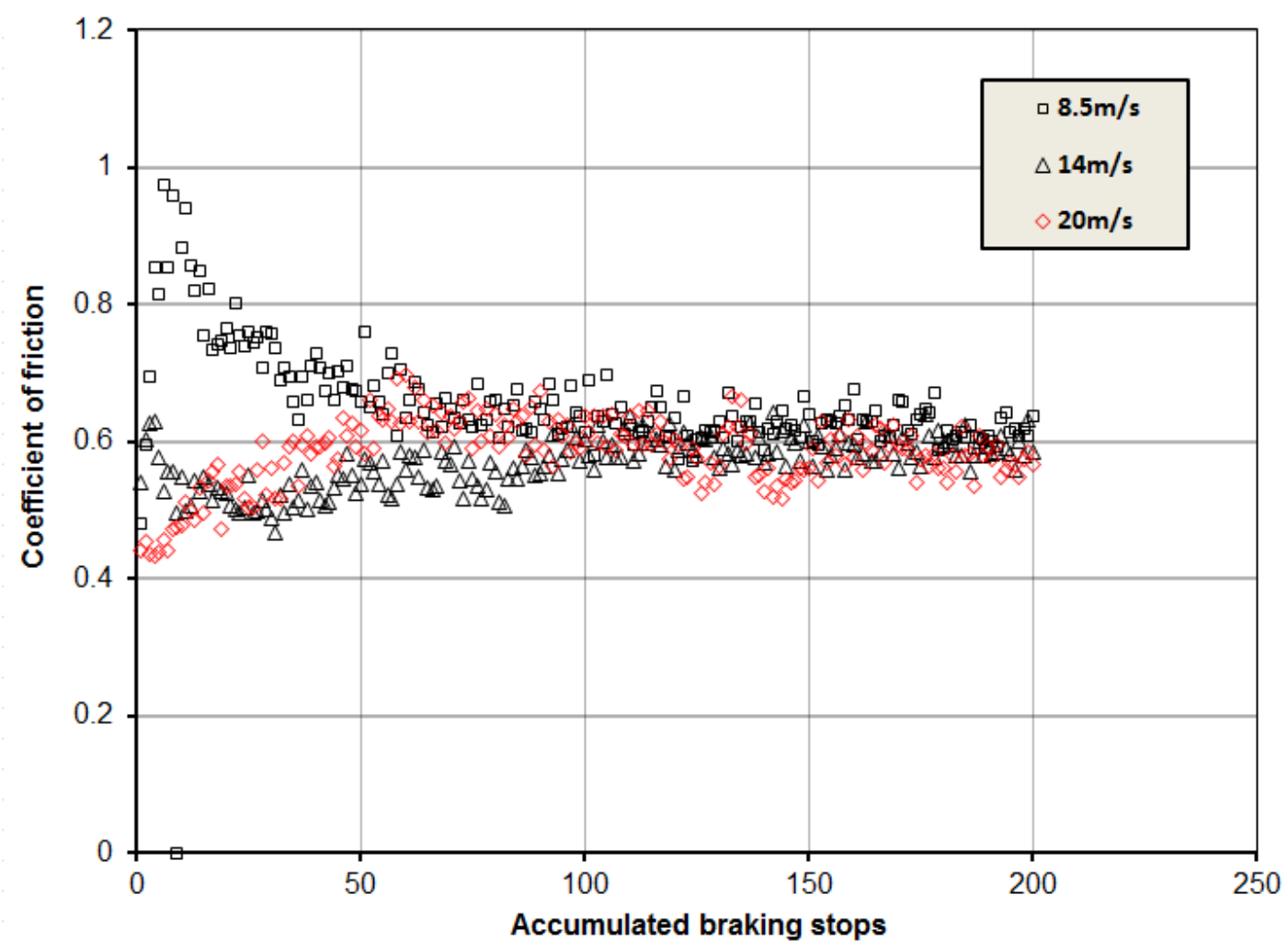

Figure 2 Measurements of averaged friction coefficient for each braking stop of a test that a SiC disc was braked by a steel pad under an initial braking speed of 8, 14 and $20 \mathrm{~m} / \mathrm{s}$. 


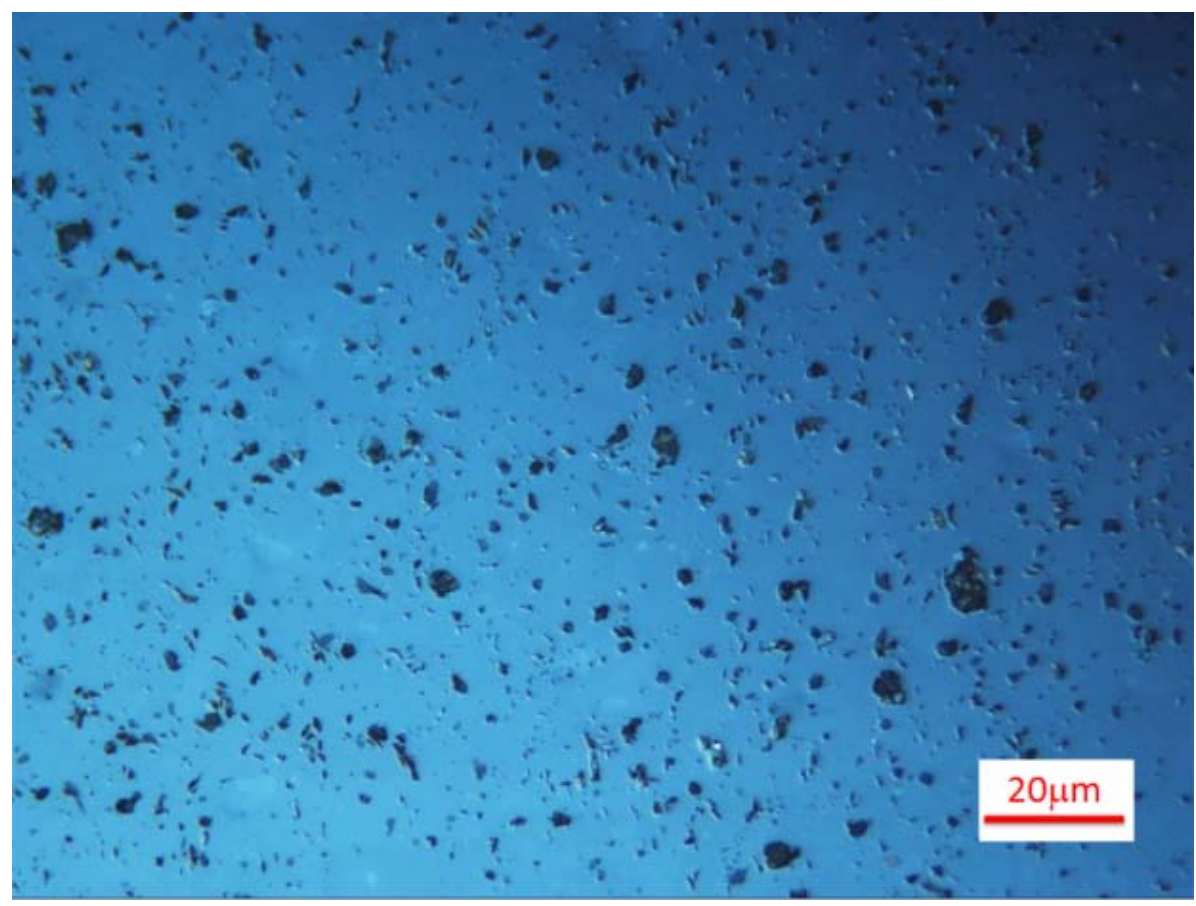

(a)

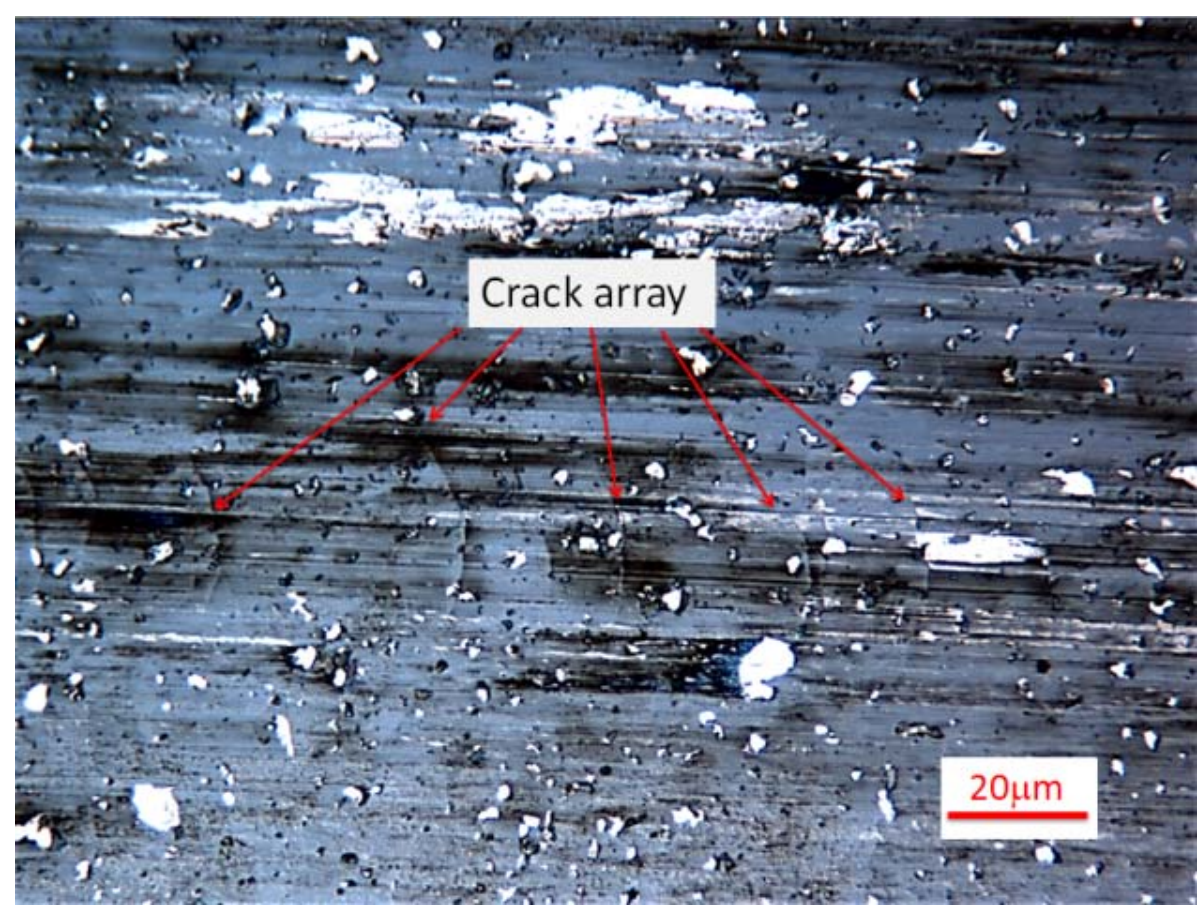

(b) 


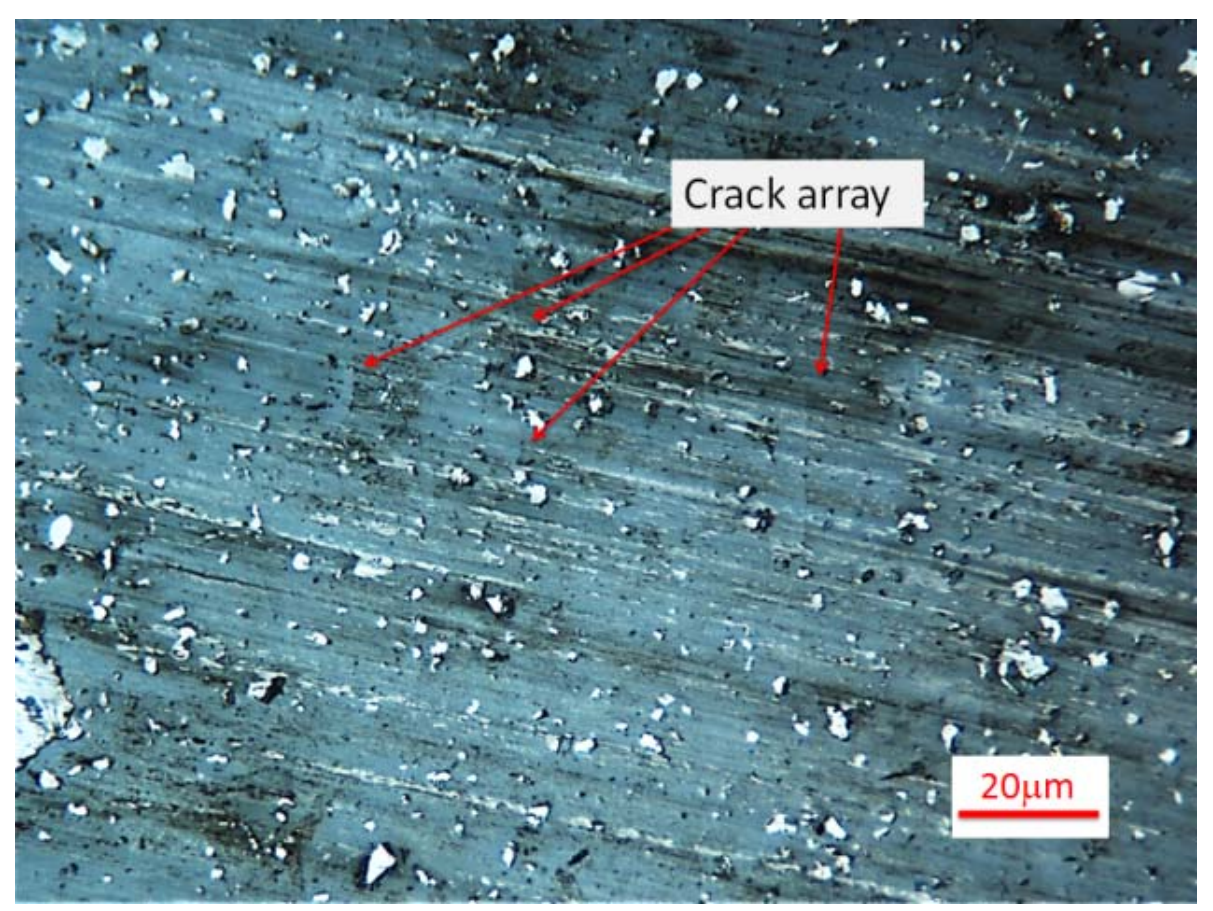

(c)

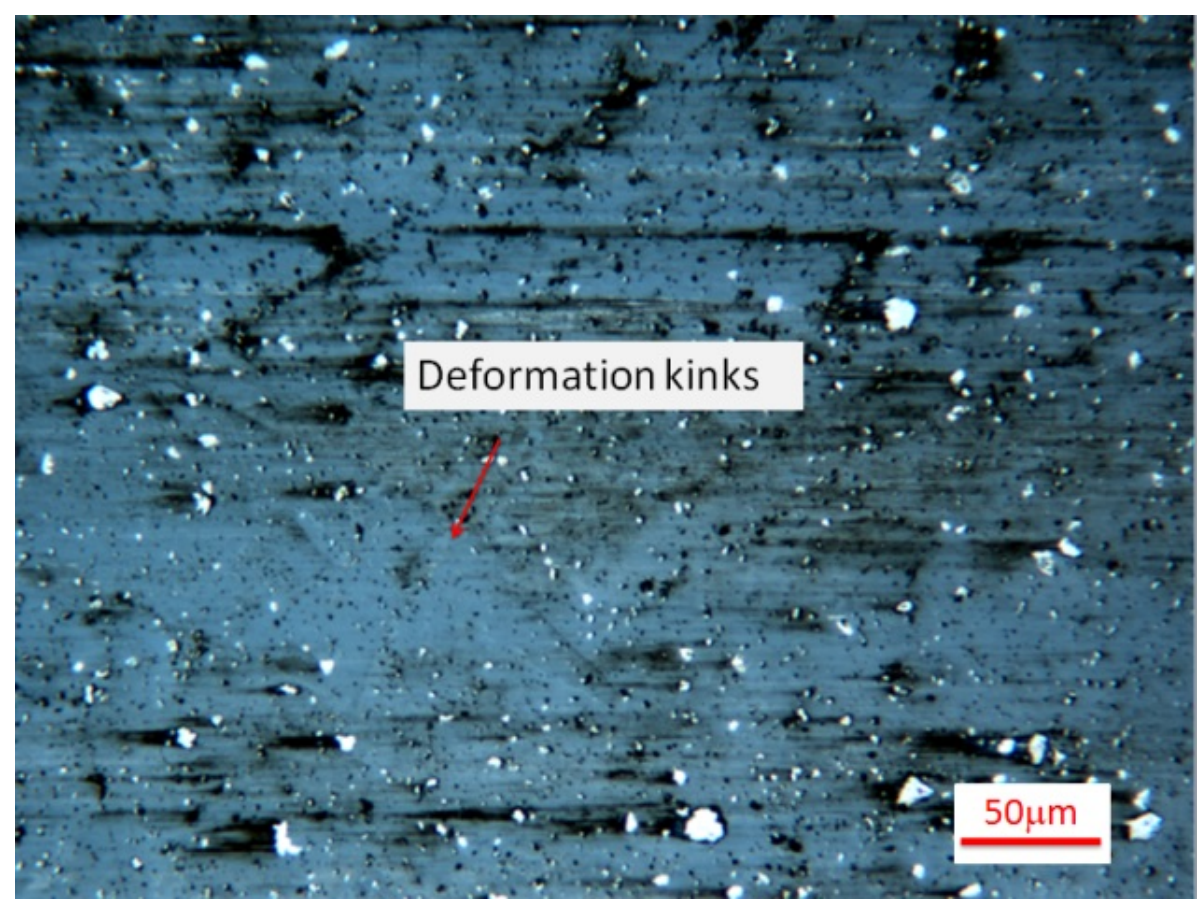

(d) 


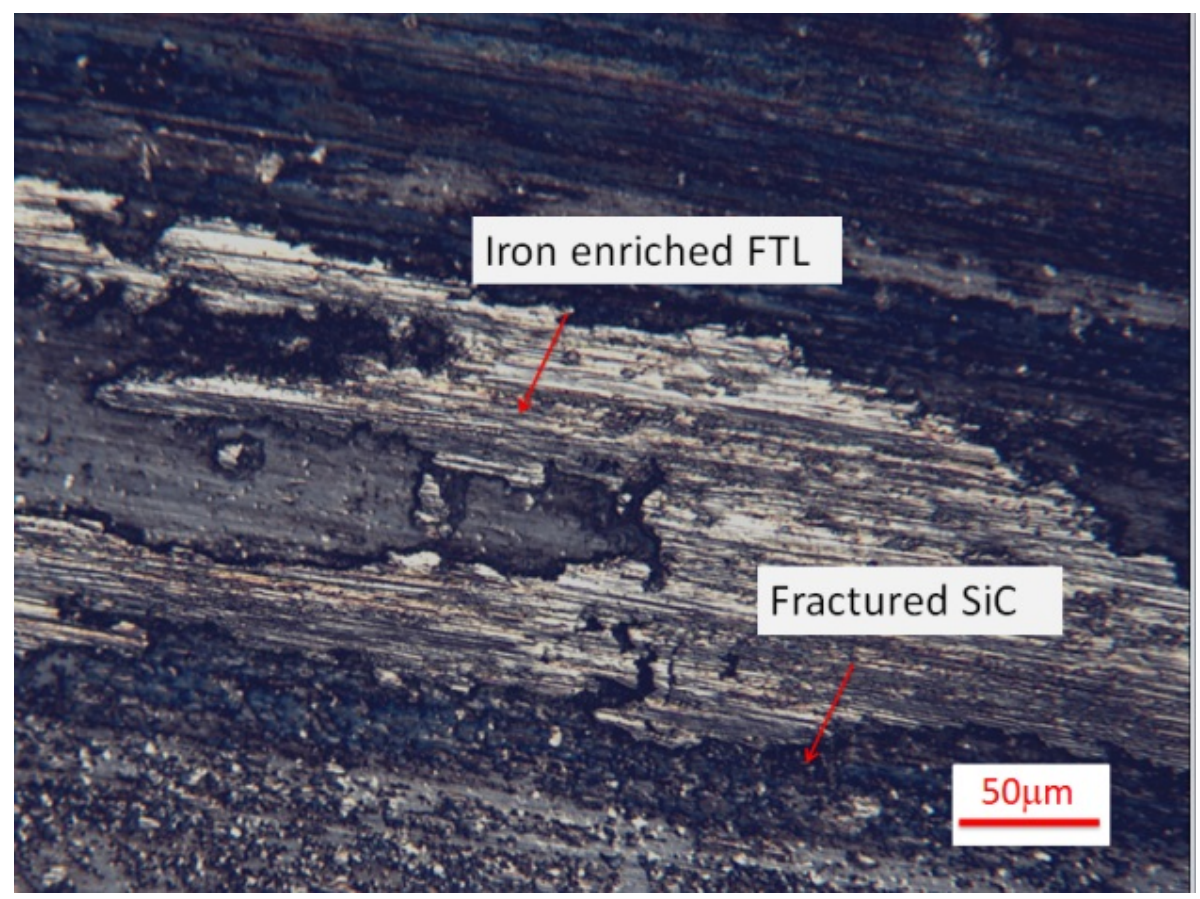

(e)

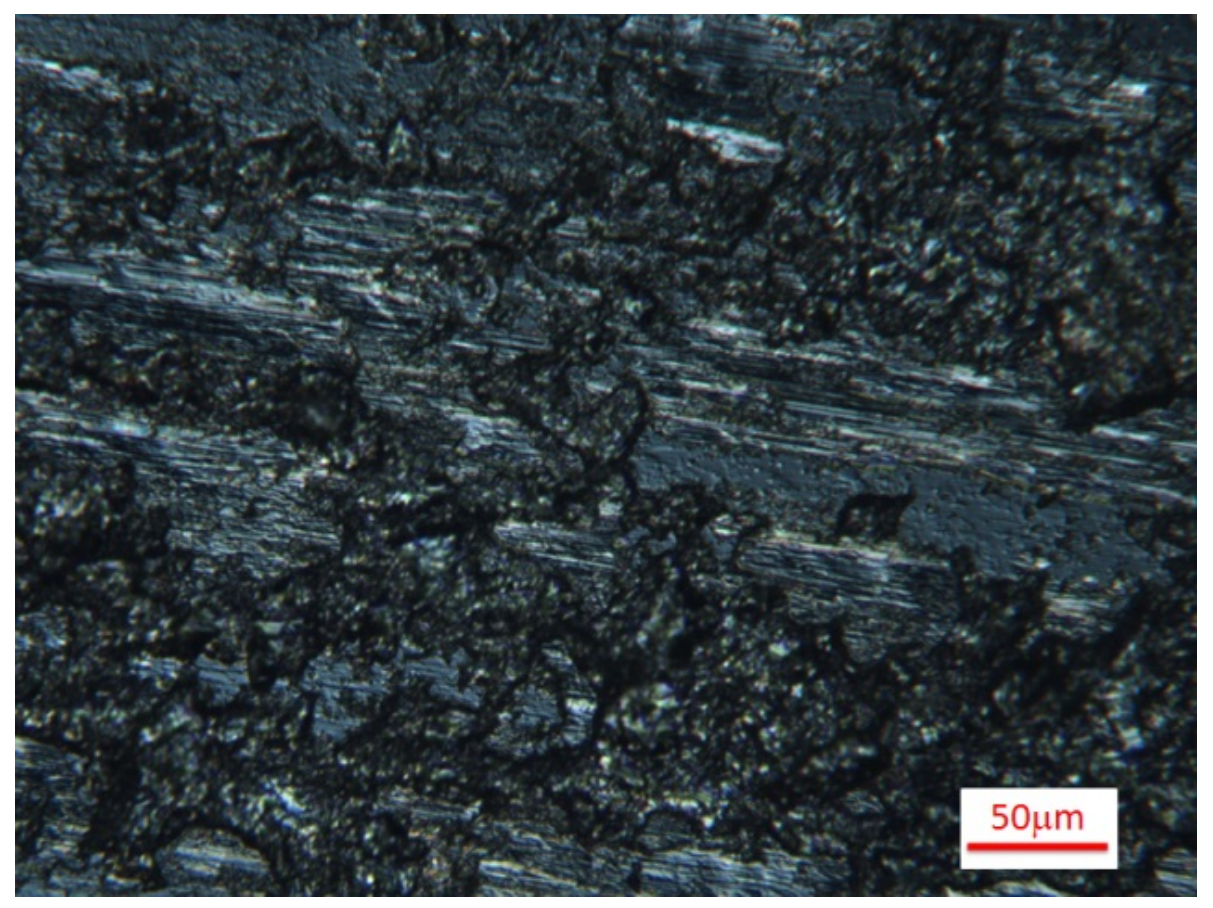

(f)

Figure 3 Representative optical microscopy images of SiC friction surface tested under a braking speed of $8.5 \mathrm{~m} / \mathrm{s}$. (a) as-polished surface; (b-c) after 4 braking stops when crescent cracks, straight cracks and deformation kinks appeared; (e) after 35 braking stops; (f) after 200 braking stops. 


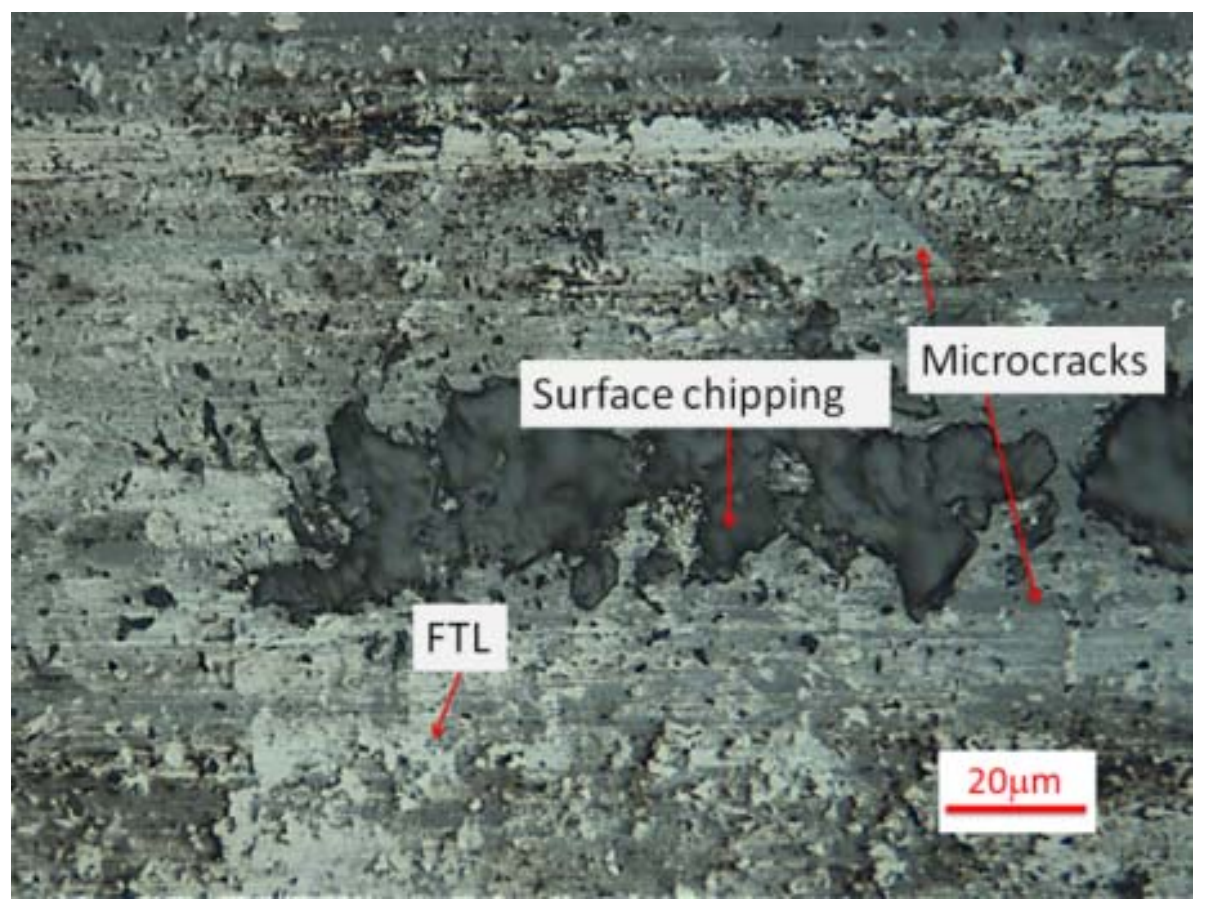

(a)

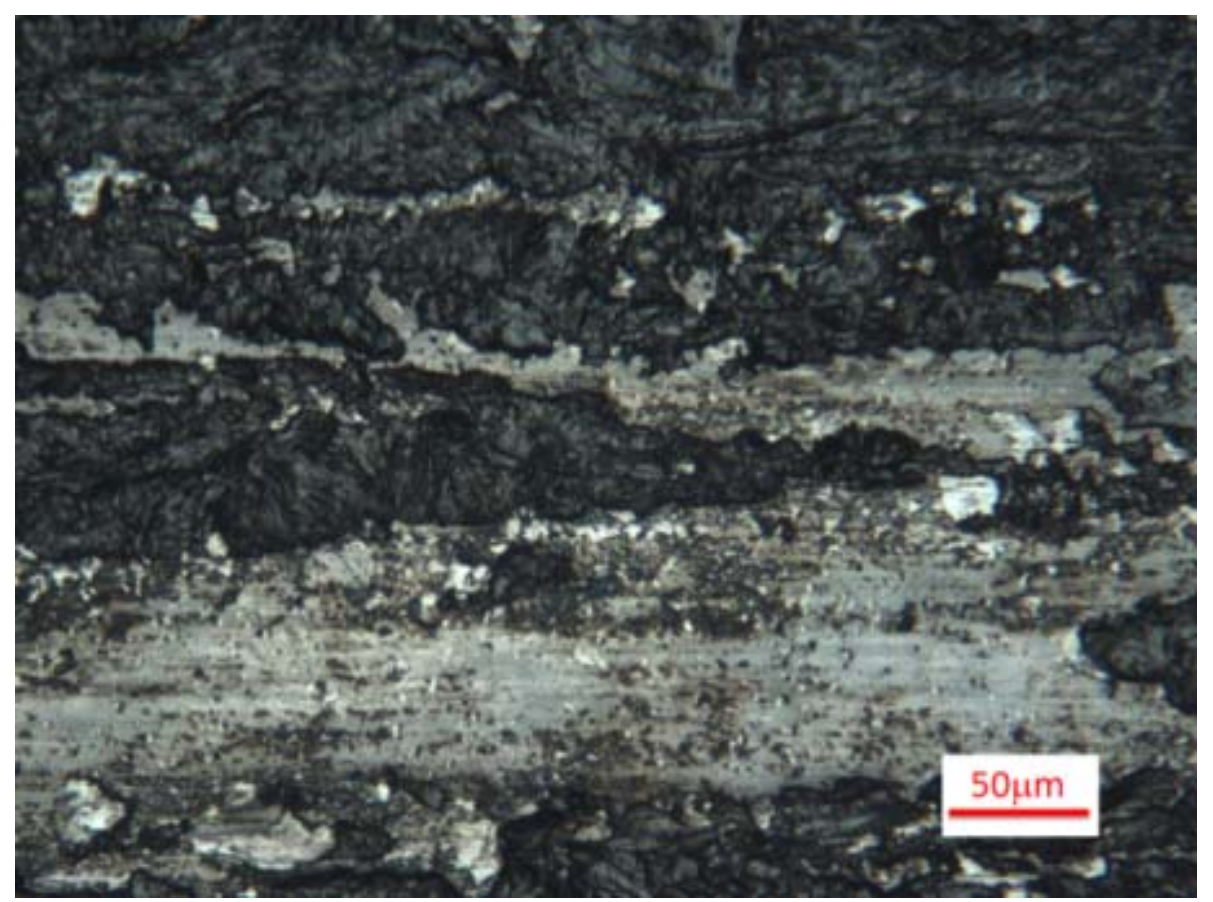

(b) 


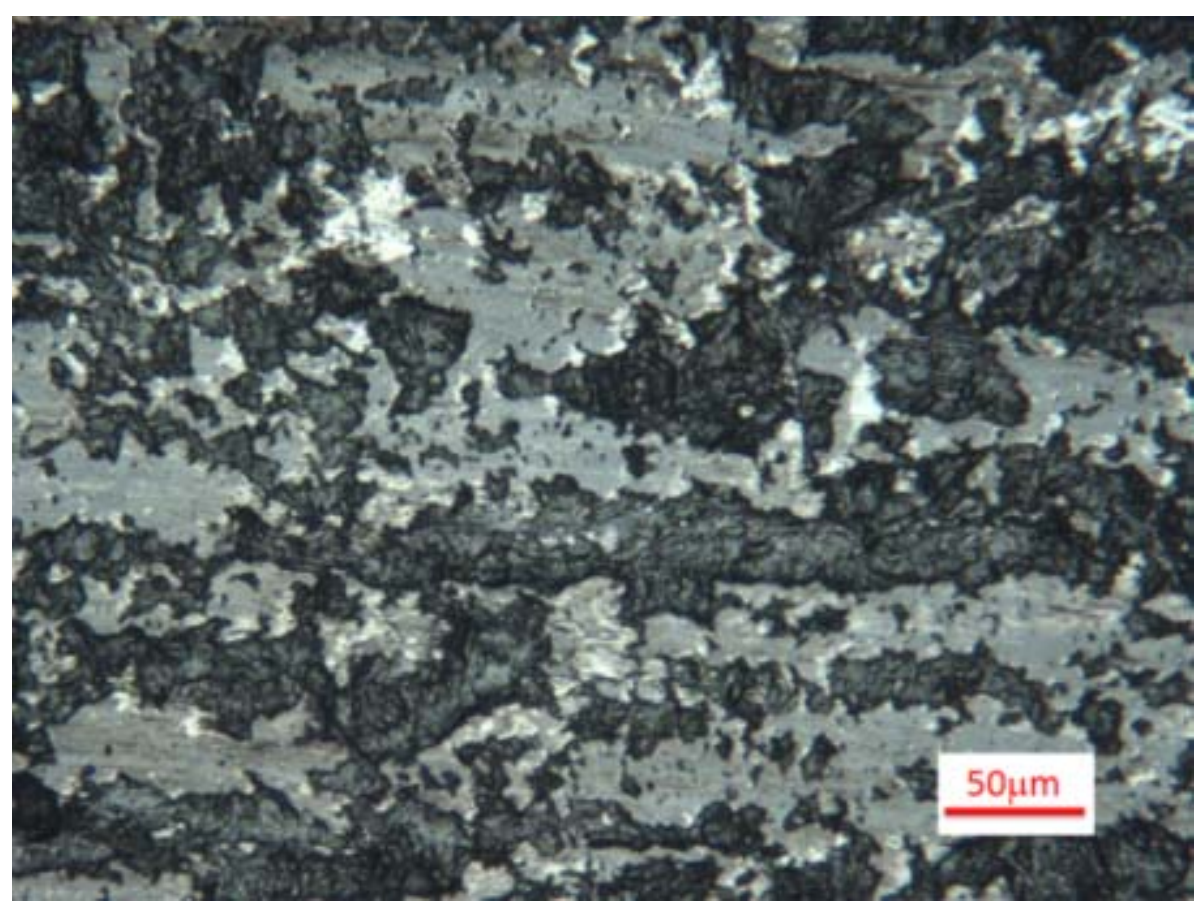

(c)

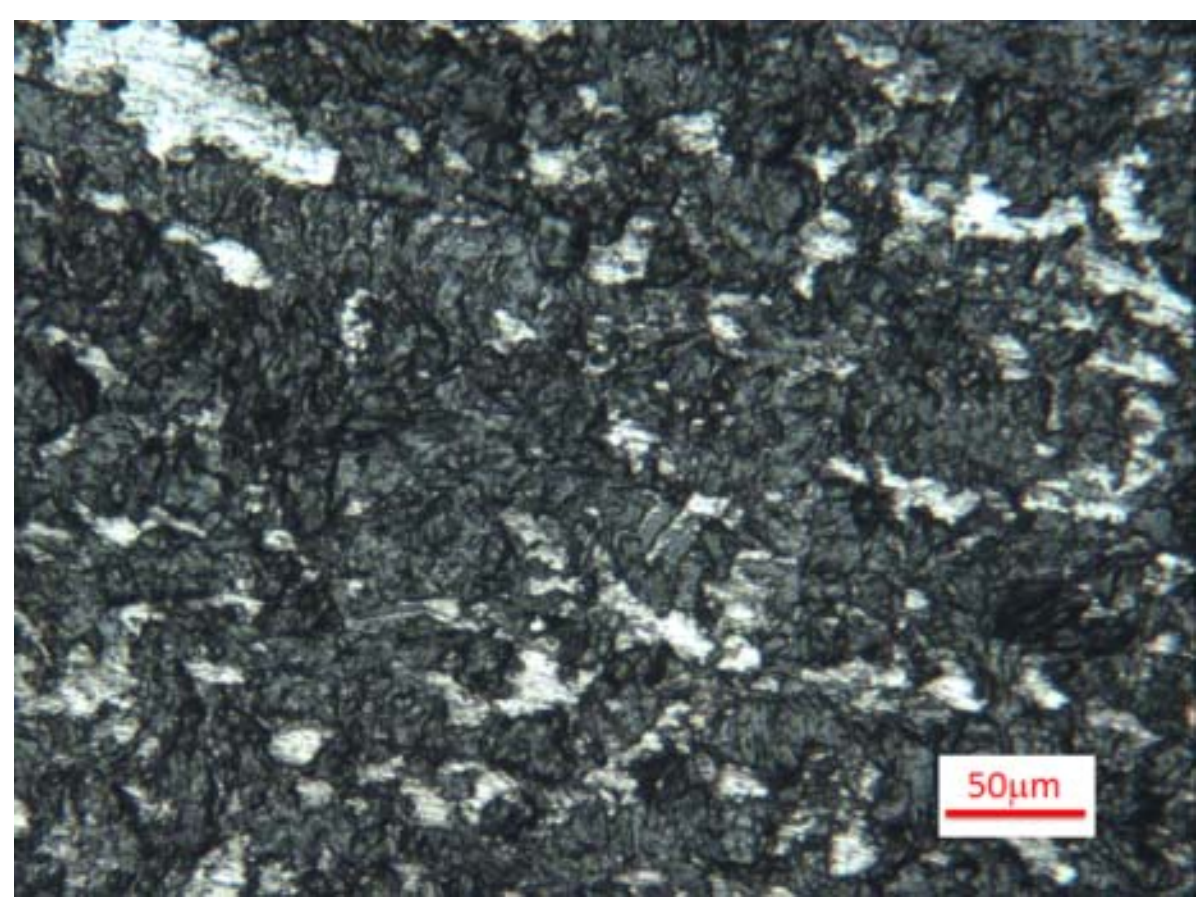

(d) 


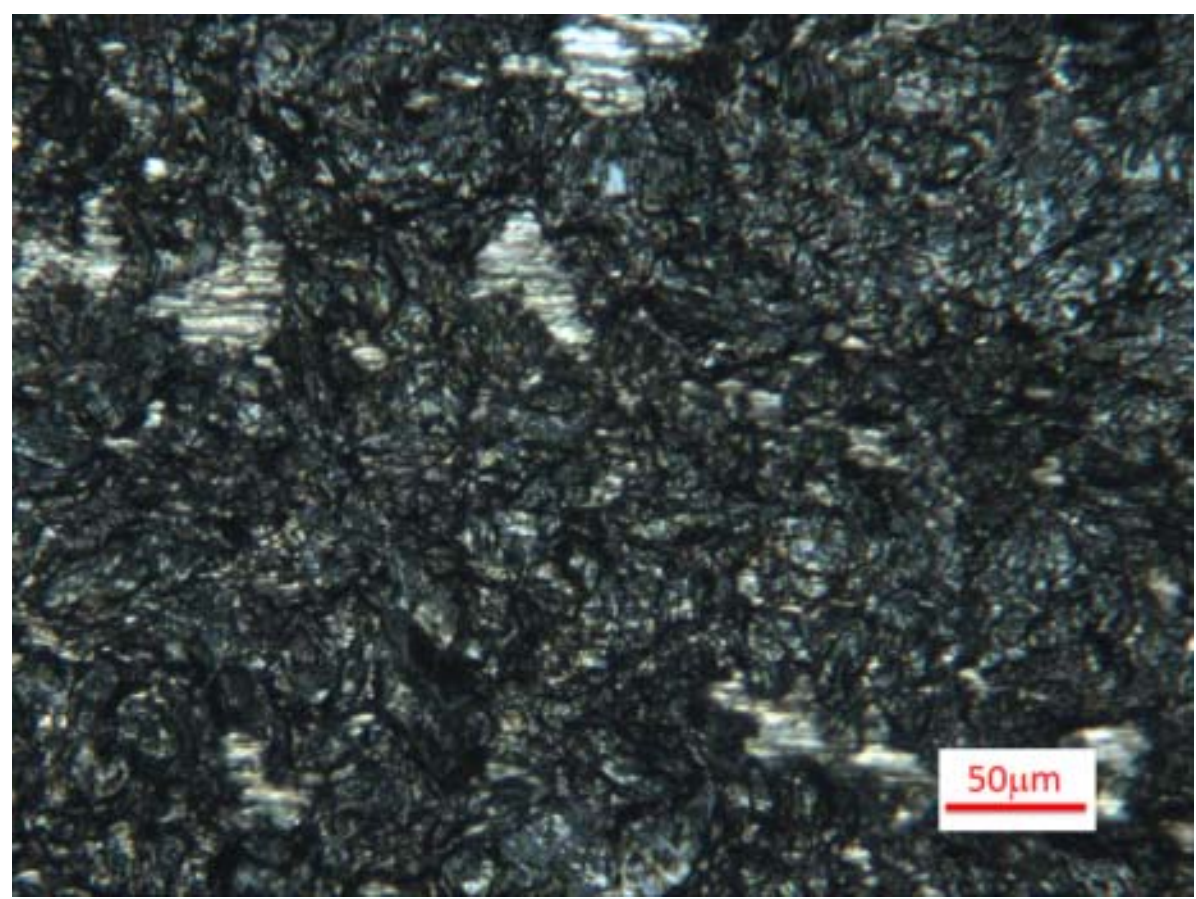

(e)

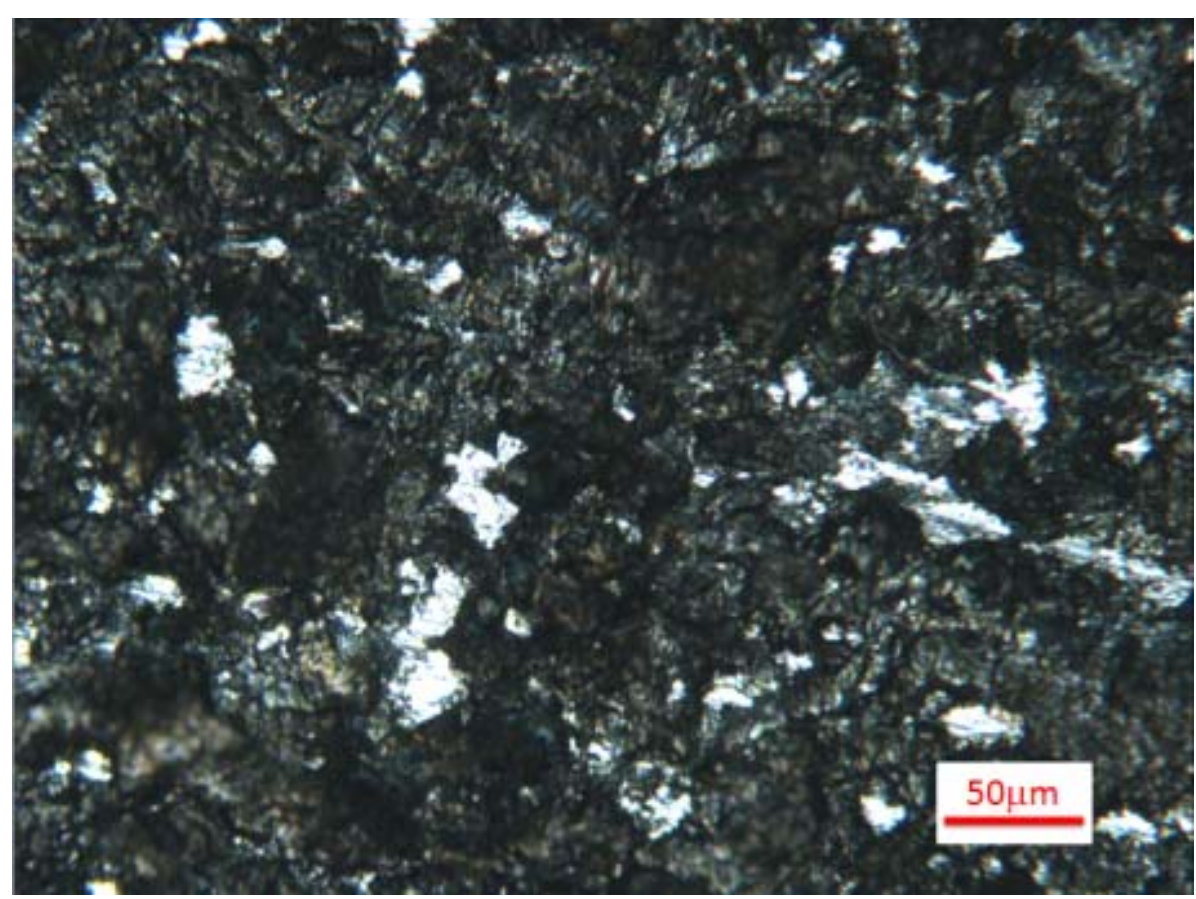

(f) 


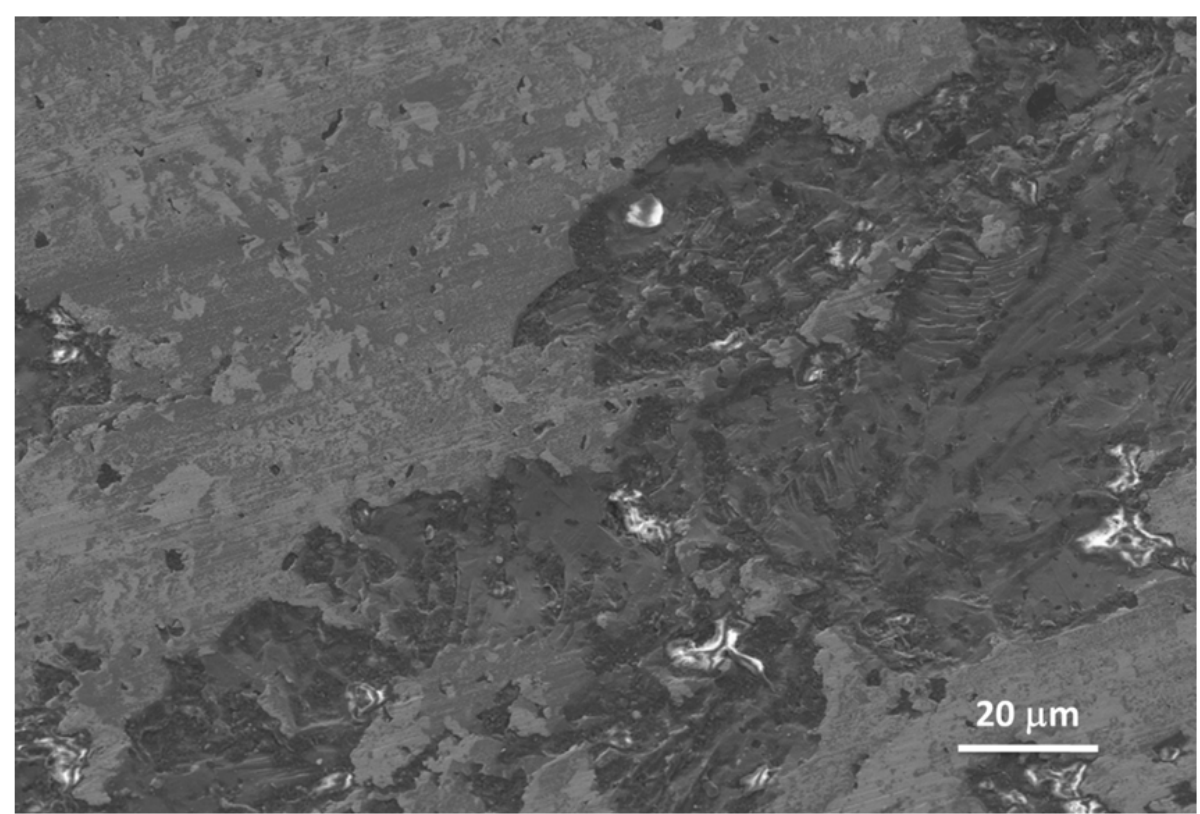

(g)

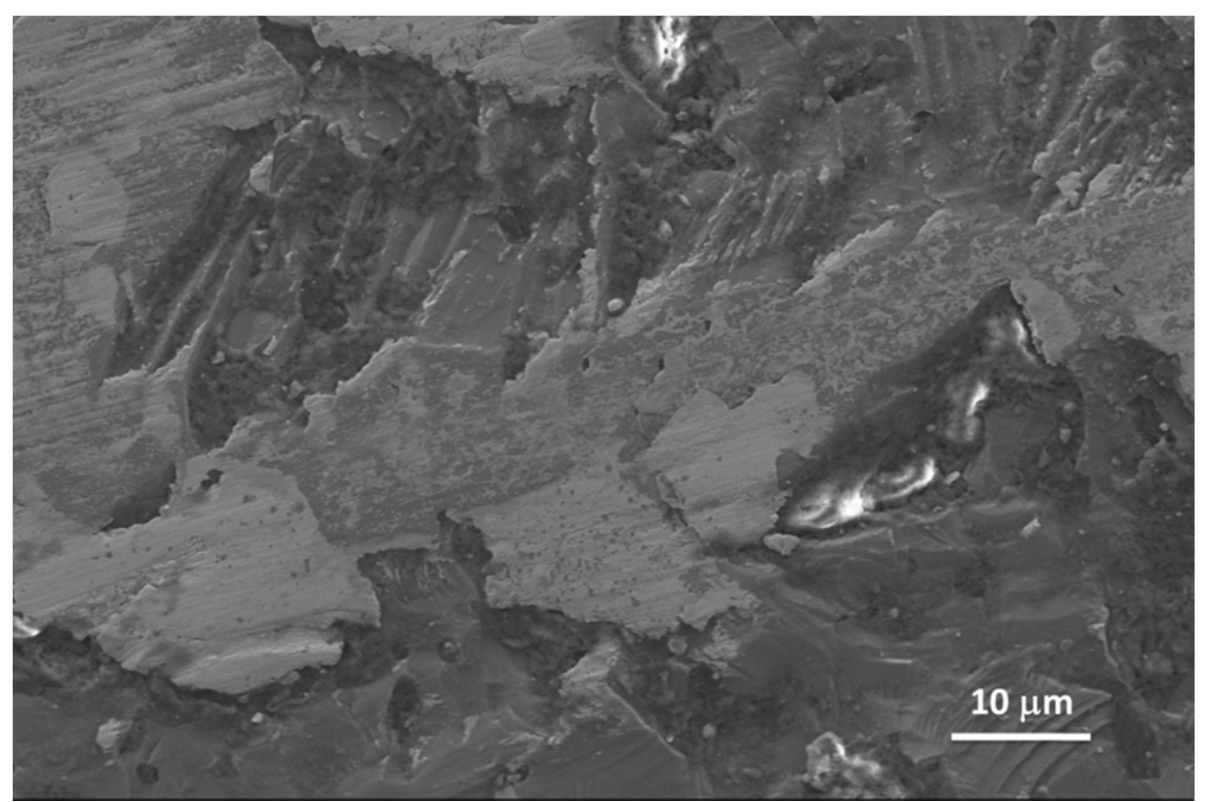

(h)

Figure 4 Representative optical microscopy (a-f) and SEM (g-h) images of SiC friction surface after braking under an initial braking speed of $20 \mathrm{~m} / \mathrm{s}$. (a) after 1 braking stop; (b) after 3 braking stops; (c) after 8 braking stops; (d) after 15 braking stops; (e) after 50 braking stops; (f) after 200 braking stops; (g-h) SEM images of the friction surface after 1 braking stops 


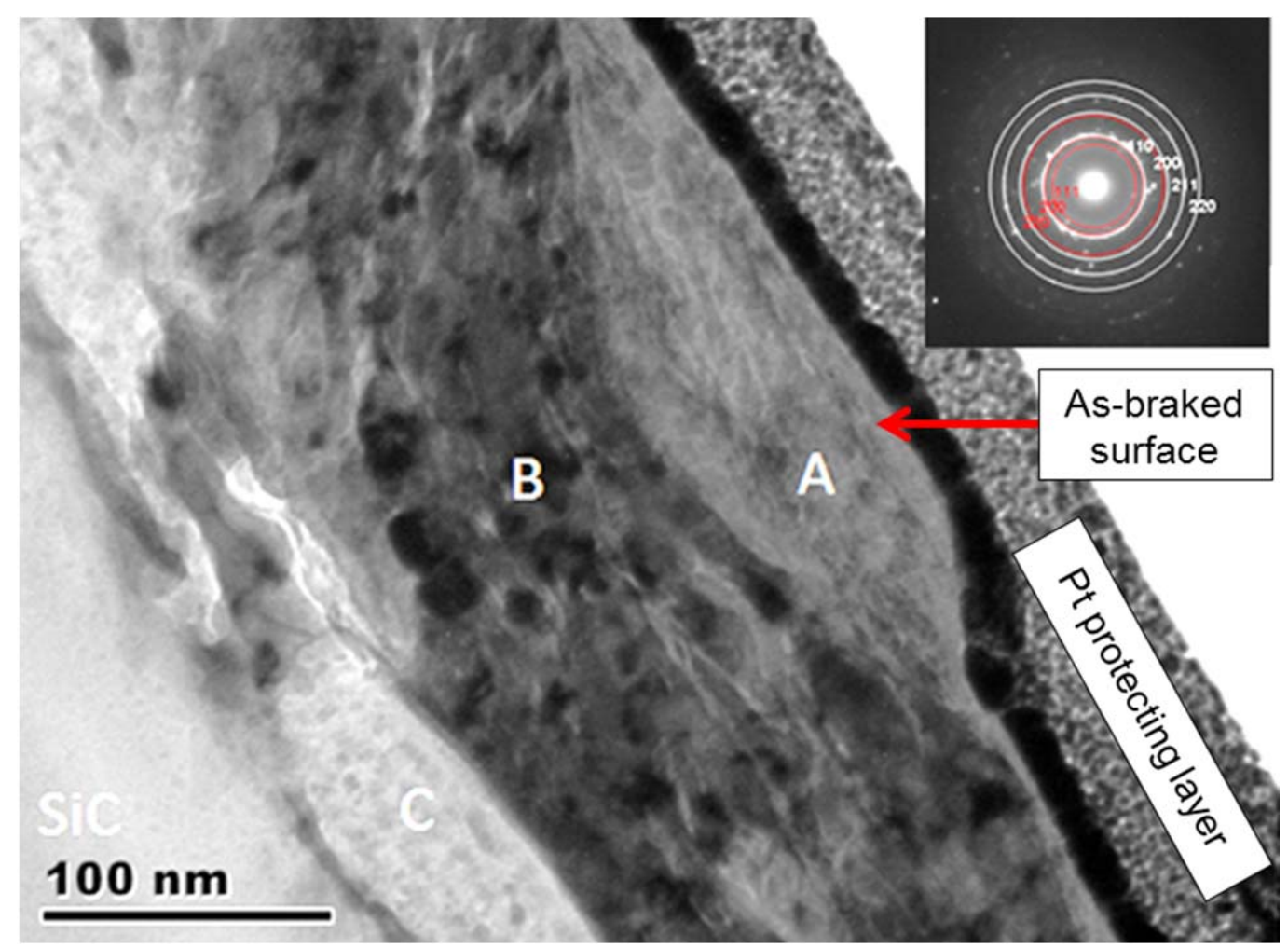

(a)

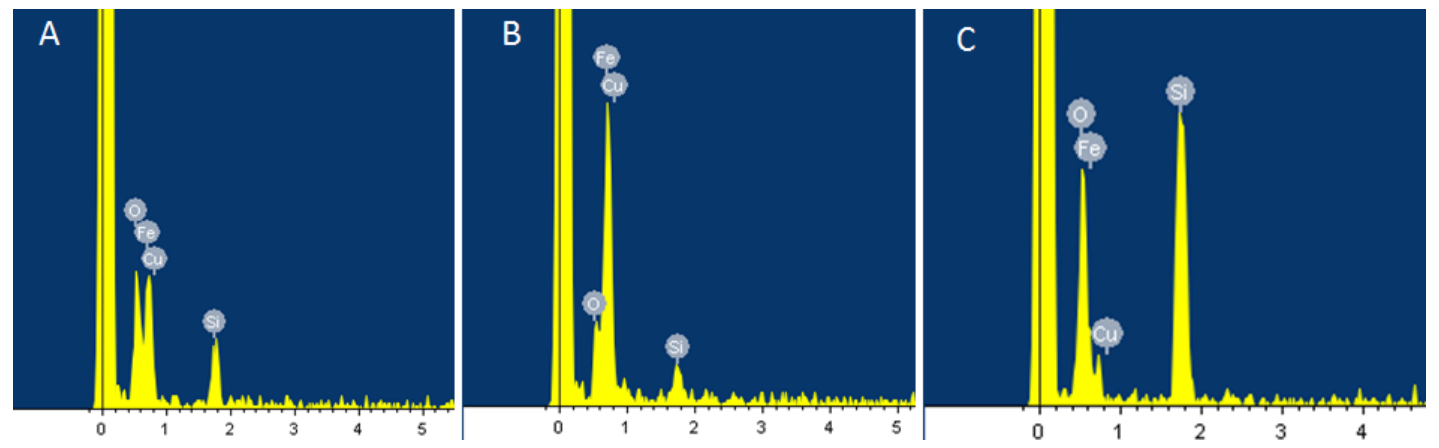

(b)

Figure 5 TEM images of a cross section of SiC friction surface after 50 braking stops under an initial braking speed of $8.5 \mathrm{~m} / \mathrm{s}$. (a) diffraction contrast image, including a representative selecting area diffraction pattern from $A$ and $B$ regions, shown as an inset; (b) representative EDX spectra showing the chemical composition in region A, $\mathrm{B}$ and $\mathrm{C}$, respectively. 


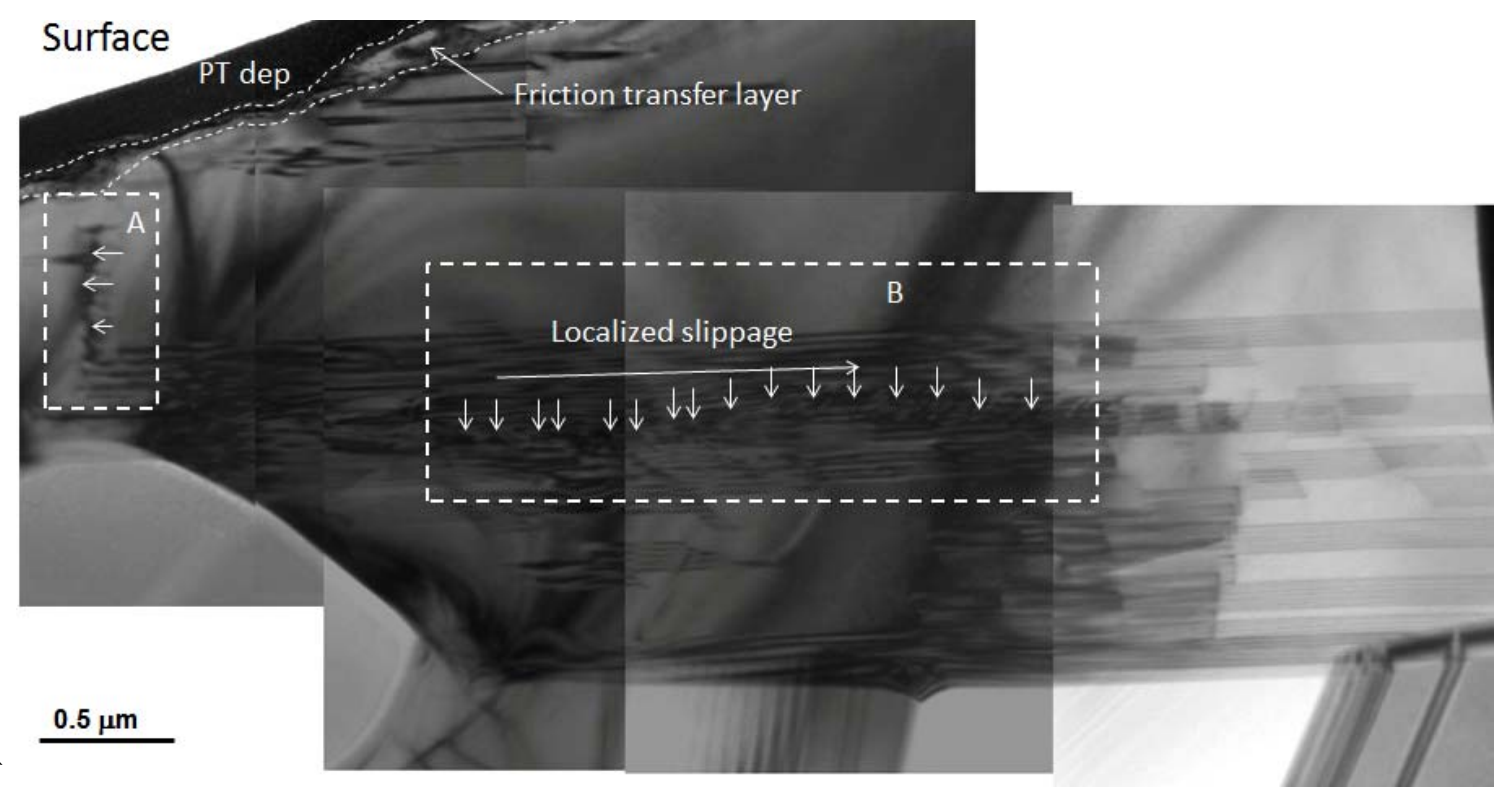

(a)

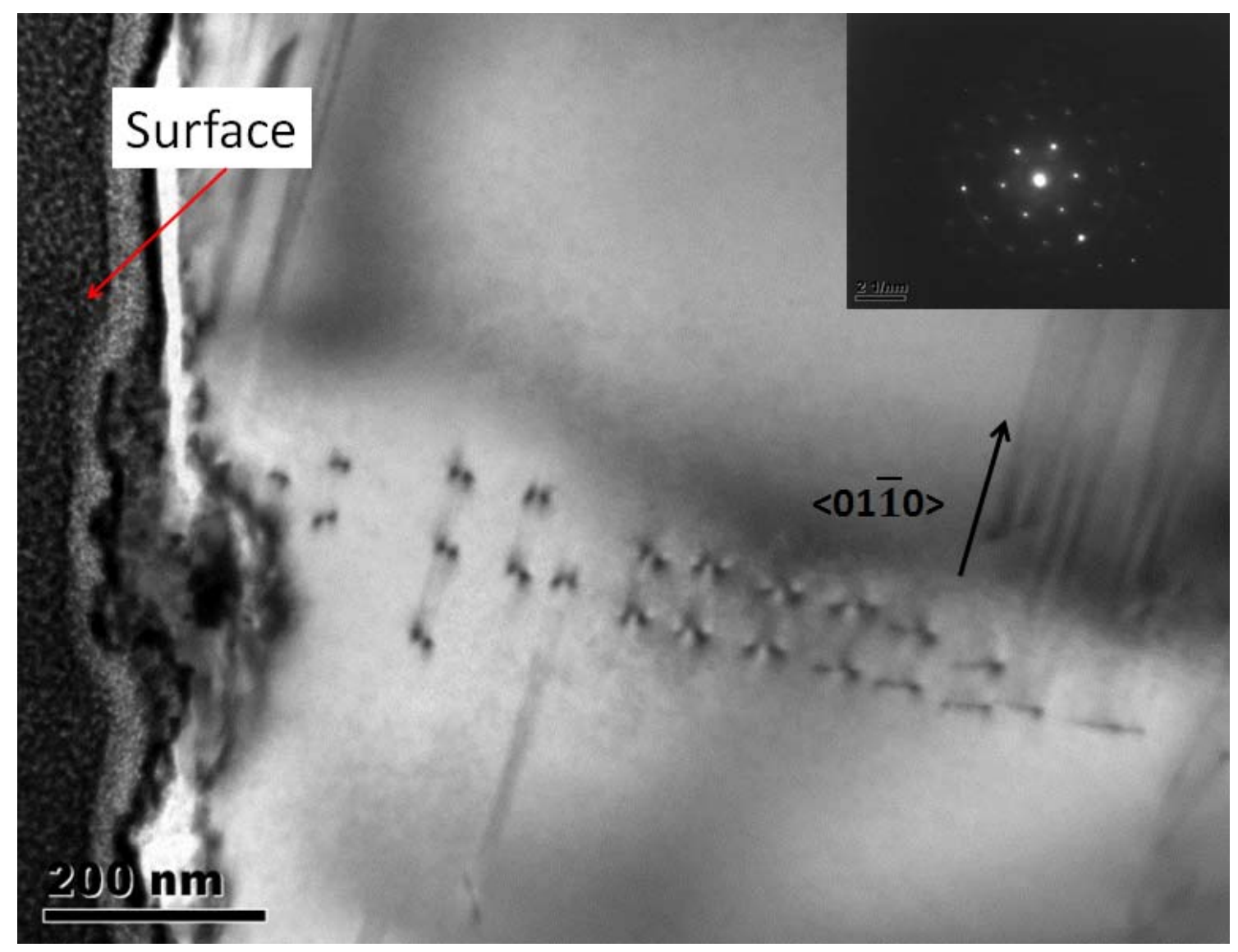

(b) 


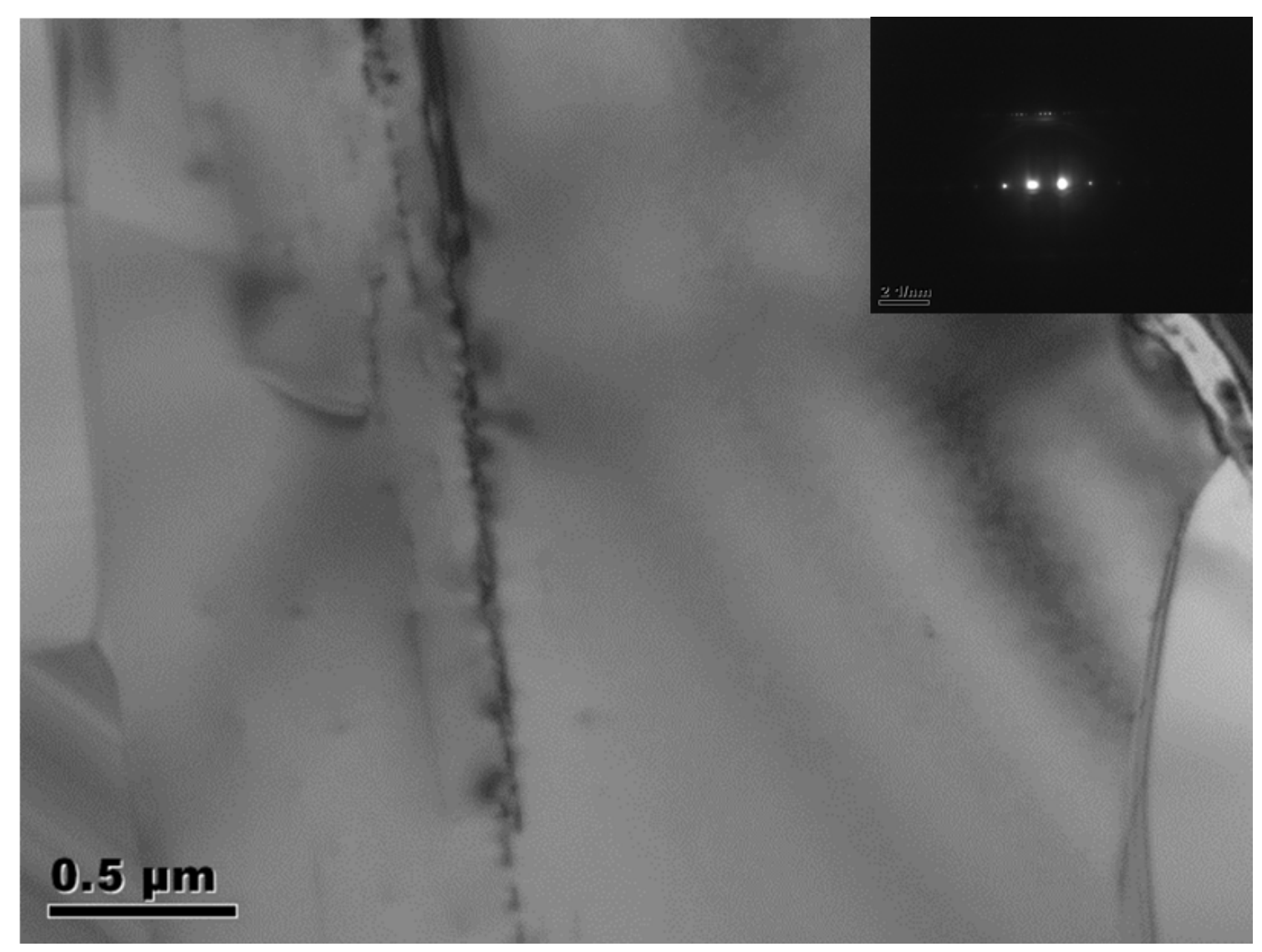

(c)

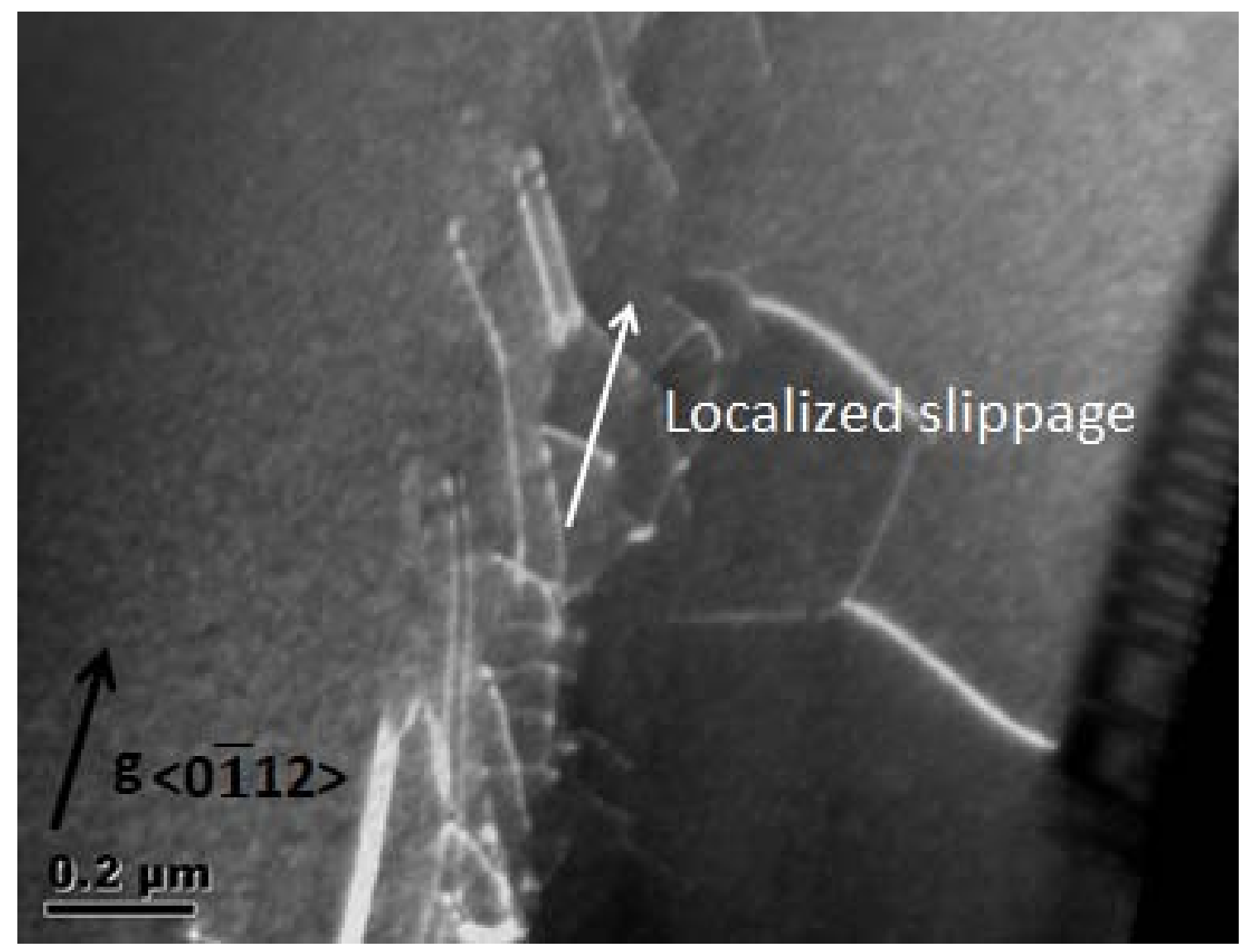

(d) 


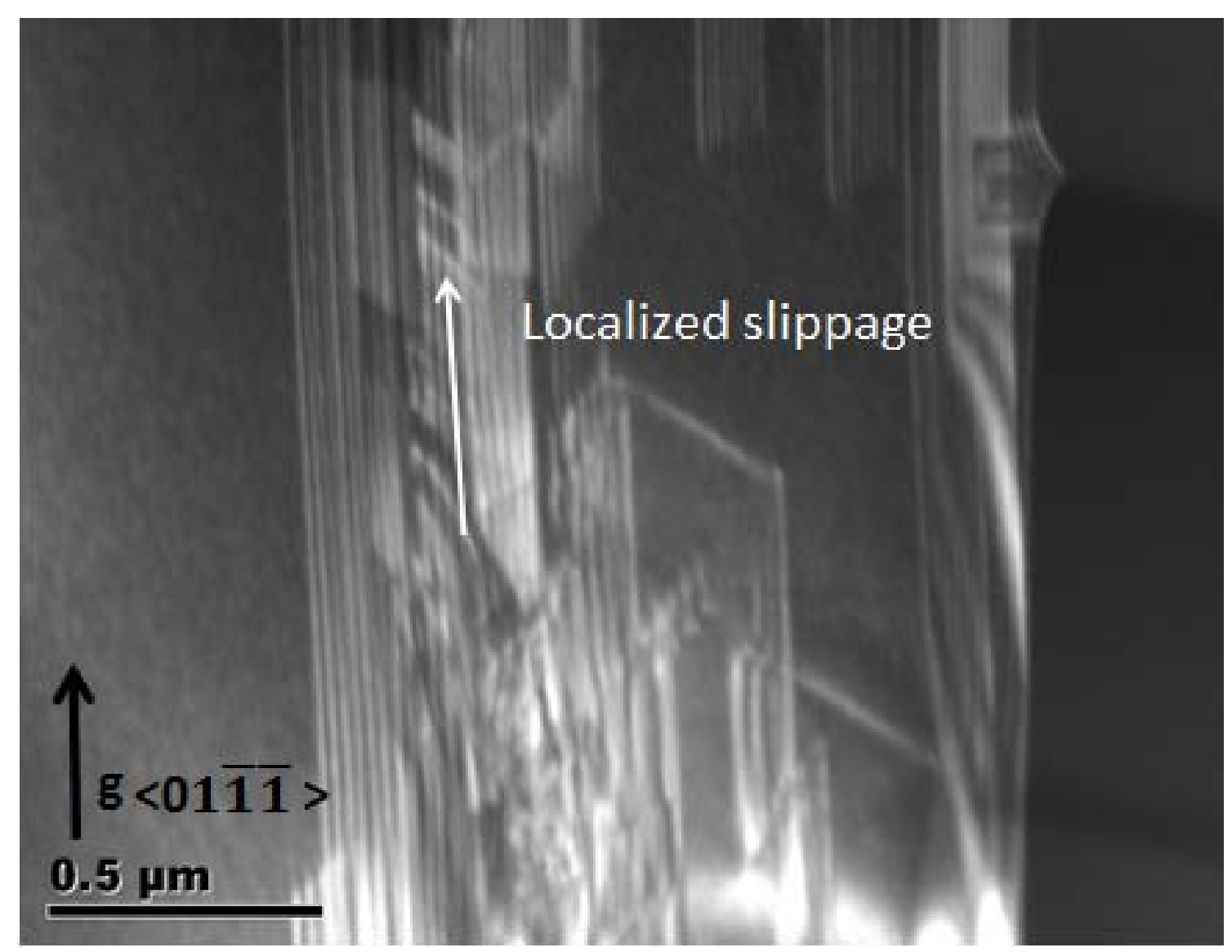

(e)

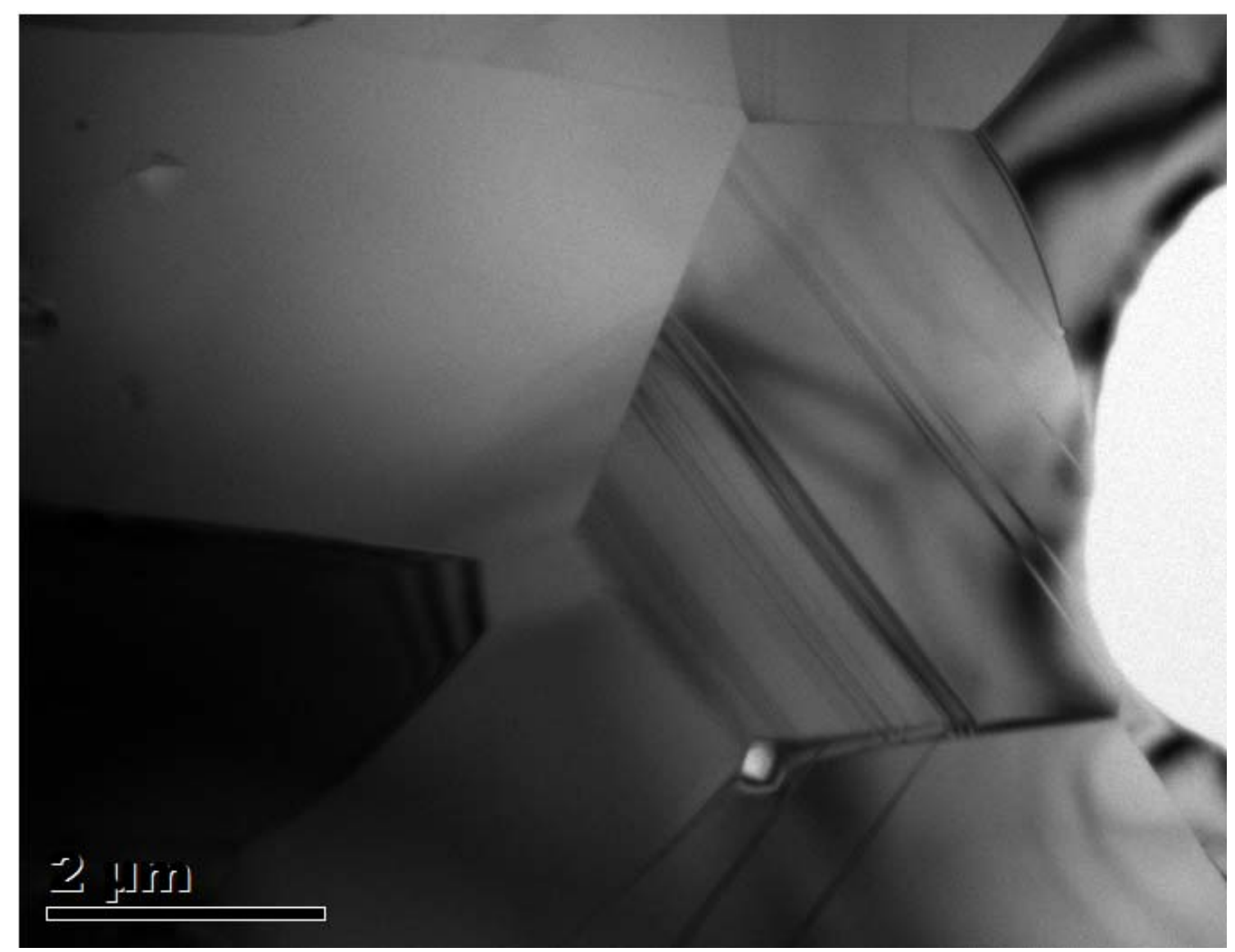

(f) 
Figure 6 Friction induced lattice defects in SiC grains underneath the friction transfer layer. (a) Diffraction contrast image showing the overview of a cross-section, where region A and B were heavily deformed. The defects were initiated from region A near the surface and followed by further slippage to region B inside the grain. (b) High magnification BF image acquired from region A, showing a serial of dislocations initiated from the contact surface and started to glide deeply inside the grain; electron beam was parallel to $\{0001\}$ zone axis. (c) High magnification BF image acquired from region $\mathrm{B}$, showing the defects were constrained in a narrow region; electron beam was tiled away from the $\{0001\}$ zone axis. (d-e) Double beam BF images acquired from region $\mathrm{B}$, confirming these defects are composed of partial dislocations with high mobility and the associated stacking faults (note the dislocations in $\mathrm{A}$ is also the partial type). (f) BF image of the microstructure of as-manufactured SiC. 


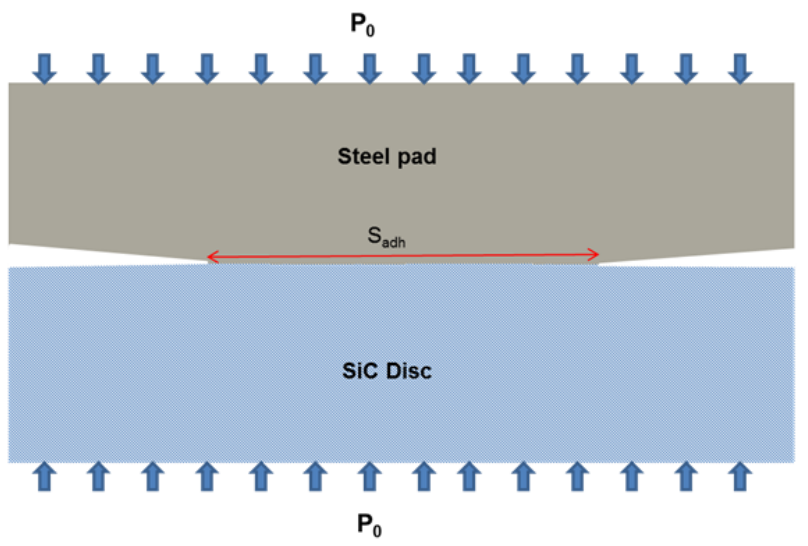

(a)
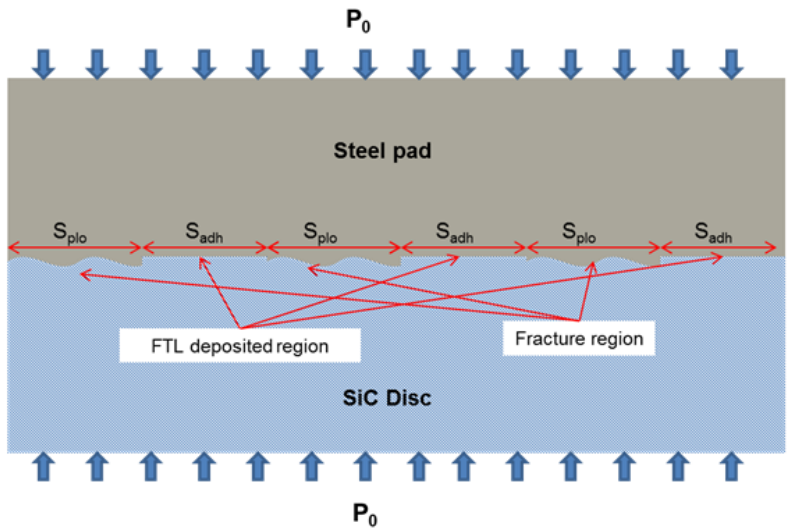

(c)

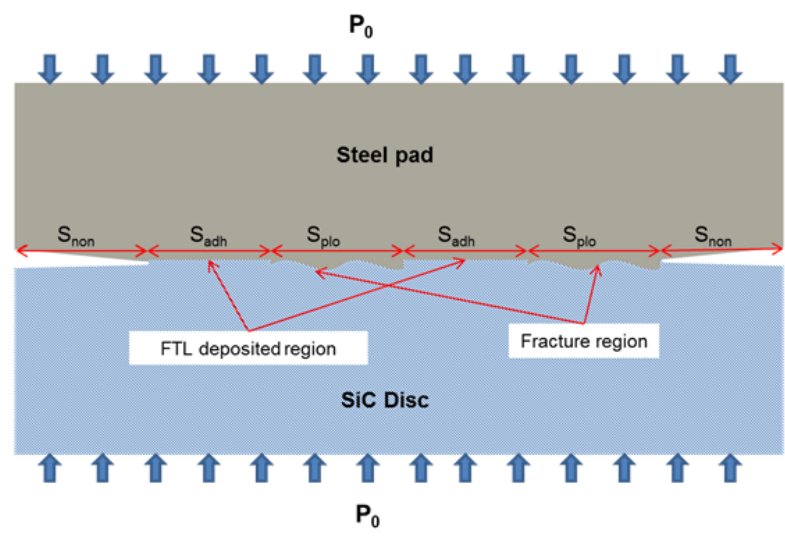

(b)
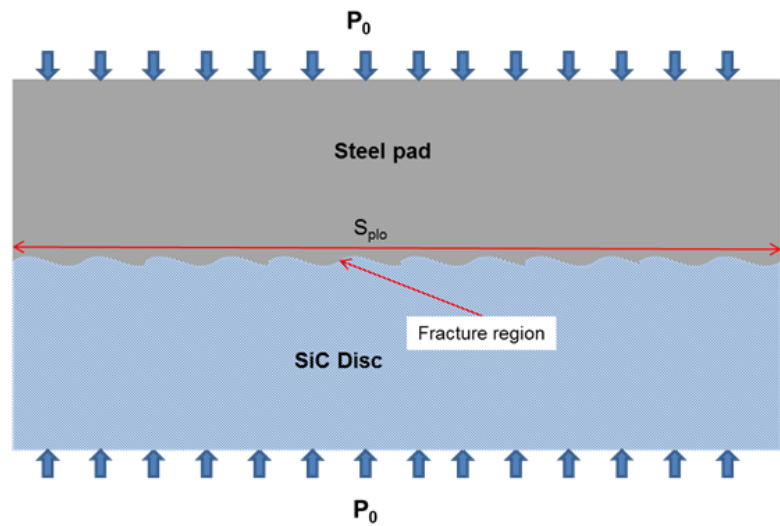

(d)

Figure 7 Schematic of the contact friction interface between a SiC disc and a steel pad at different stage of the friction test. (a) The initial contact showing noncontact regions $\left(S_{n o n}\right)$ and flat contact regions $\left(S_{a d h}\right)$. (b) The early stage contact showing noncontact regions, flat contact regions, and contact regions consisting of fracture surface in SiC $\left(\mathrm{S}_{\mathrm{plo}}\right)$. (c) The middle stage contact showing flat contact regions and contact regions consisting of fracture surface in SiC. (d) The stable stage showing one type of contact consisting of surface fracture in SiC. S represents the area of each type of region and $\mathrm{P}_{0}$ the braking pressure. 


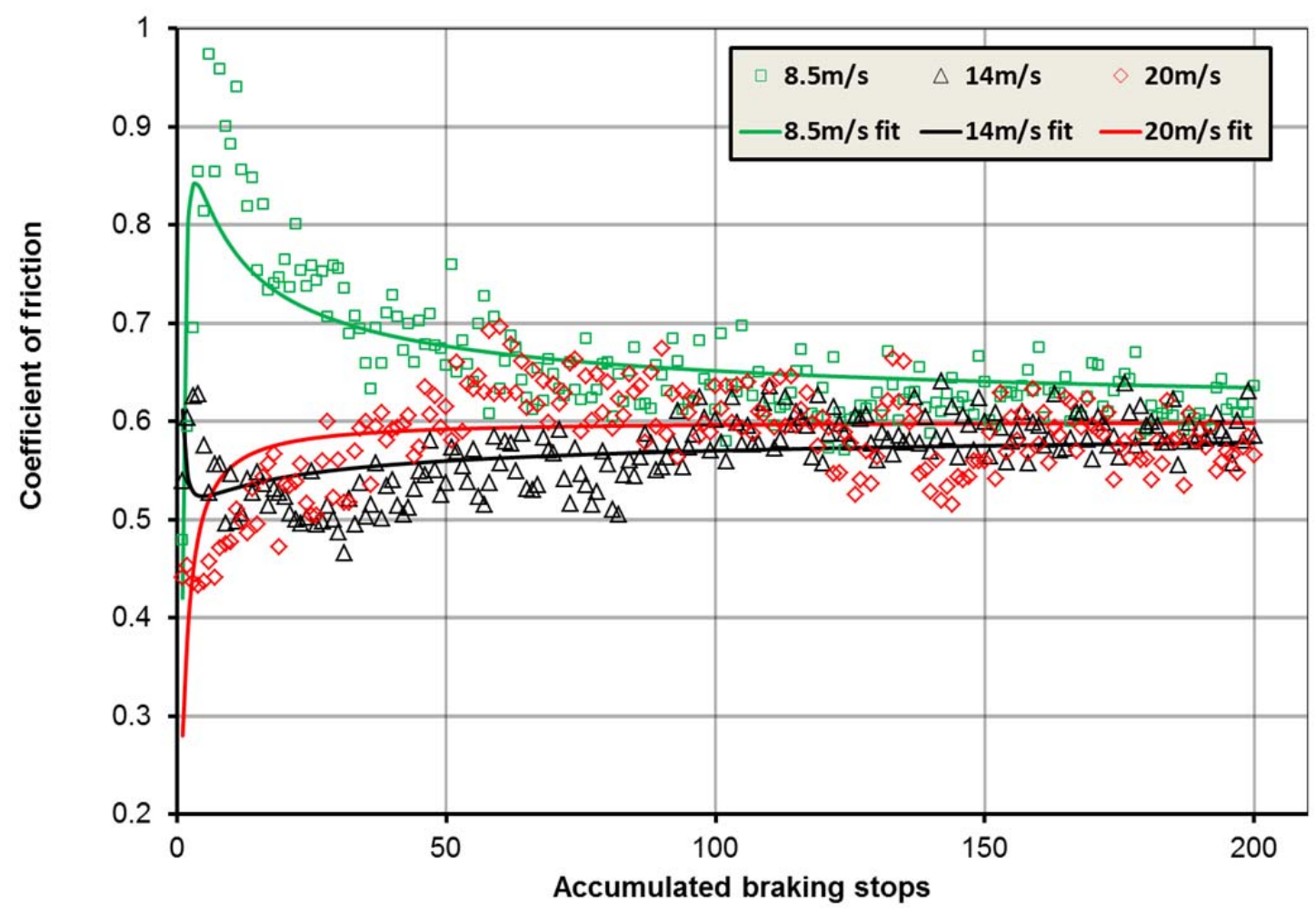

(a)

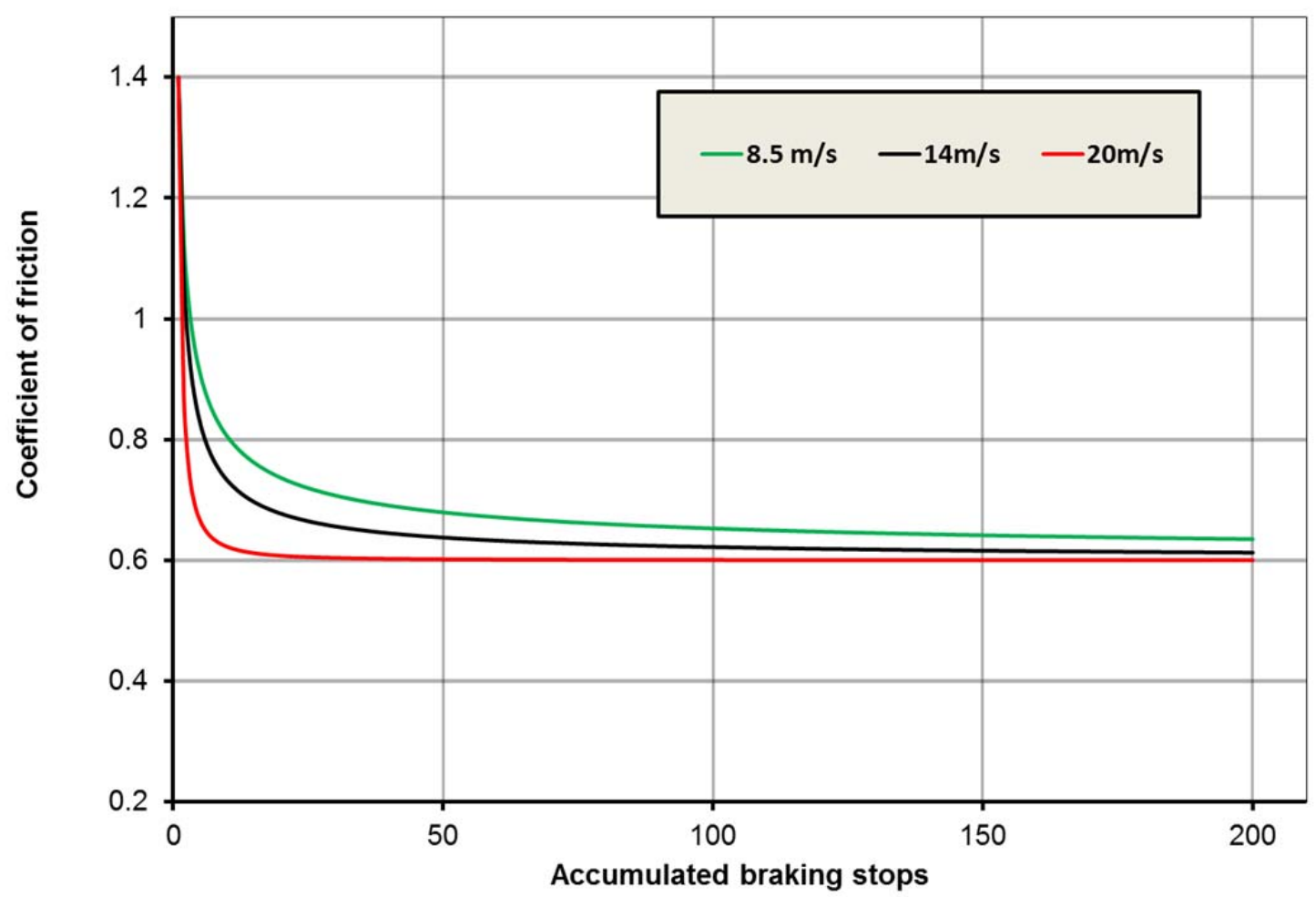

(b) 
Figure 8 (a) The trend of averaged friction coefficient varies with the accumulated braking stops predicted by eq. (13), derived from a friction model that consists of fracture surface contact, flat surface contact and non-contact. The trend was fitted by using least square method. (b) The estimated variation of fiction coefficient with braking stop number when the friction components are in complete contact during testing, as predicted by eq. (14). 
Table 1 Summary of values of $m, k$ and $a$ included in eq. (13) under different braking initial speed.

\begin{tabular}{|c|c|c|c|}
\hline $\begin{array}{c}\text { Initial baking } \\
\text { speed }(\mathbf{m} / \mathbf{s})\end{array}$ & $\mathbf{m}$ & $\mathbf{k}$ & $\mathbf{b}$ \\
\hline $\mathbf{8 . 5}$ & 0.59 & 1.56 & 0.70 \\
\hline $\mathbf{1 4}$ & 0.78 & 0.59 & 0.56 \\
\hline $\mathbf{2 0}$ & 1.55 & 1.21 & 0.8 \\
\hline
\end{tabular}


Estimated fraction of fracture surface generated by each braking stop and the ratios among braking under different initial braking speed.

\begin{tabular}{|c|c|c|c|c|c|c|}
\hline \multirow[b]{2}{*}{$\begin{array}{l}\text { Braking } \\
\text { number }\end{array}$} & \multicolumn{3}{|c|}{$\begin{array}{l}\text { Fraction of fracture surface } \\
\text { generated by each braking } \\
\text { stop } \\
\left(\Delta f_{\text {plo }}\right)\end{array}$} & \multicolumn{3}{|c|}{$\begin{array}{l}\text { Ratio of } \Delta f_{\text {plo }} \text { under different } \\
\text { initial braking speed }\end{array}$} \\
\hline & $8.5 \mathrm{~m} / \mathrm{s}$ & $14 \mathrm{~m} / \mathrm{s}$ & $20 \mathrm{~m} / \mathrm{s}$ & $8.5 \mathrm{~m} / \mathrm{s}$ & $14 \mathrm{~m} / \mathrm{s}$ & $20 \mathrm{~m} / \mathrm{s}$ \\
\hline 1 & 0.32 & 0.42 & 0.69 & 1.00 & 1.32 & 2.16 \\
\hline 2 & 0.20 & 0.27 & 0.49 & 1.00 & 1.36 & 2.46 \\
\hline 3 & 0.15 & 0.20 & 0.38 & 1.00 & 1.37 & 2.61 \\
\hline 4 & 0.12 & 0.16 & 0.31 & 1.00 & 1.38 & 2.69 \\
\hline 5 & 0.10 & 0.13 & 0.26 & 1.00 & 1.39 & 2.75 \\
\hline 6 & 0.08 & 0.11 & 0.23 & 1.00 & 1.39 & 2.79 \\
\hline 7 & 0.07 & 0.10 & 0.20 & 1.00 & 1.40 & 2.82 \\
\hline 8 & 0.06 & 0.09 & 0.18 & 1.00 & 1.40 & 2.85 \\
\hline 9 & 0.06 & 0.08 & 0.16 & 1.00 & 1.40 & 2.87 \\
\hline 10 & 0.05 & 0.07 & 0.15 & 1.00 & 1.40 & 2.88 \\
\hline 11 & 0.05 & 0.07 & 0.14 & 1.00 & 1.40 & 2.89 \\
\hline 12 & 0.04 & 0.06 & 0.13 & 1.00 & 1.41 & 2.91 \\
\hline 13 & 0.04 & 0.06 & 0.12 & 1.00 & 1.41 & 2.91 \\
\hline 14 & 0.04 & 0.05 & 0.11 & 1.00 & 1.41 & 2.92 \\
\hline 15 & 0.03 & 0.05 & 0.10 & 1.00 & 1.41 & 2.93 \\
\hline 16 & 0.03 & 0.05 & 0.10 & 1.00 & 1.41 & 2.94 \\
\hline 17 & 0.03 & 0.04 & 0.09 & 1.00 & 1.41 & 2.95 \\
\hline 18 & 0.03 & 0.04 & 0.09 & 1.00 & 1.41 & 2.95 \\
\hline 19 & 0.03 & 0.04 & 0.08 & 1.00 & 1.41 & 2.95 \\
\hline 20 & 0.03 & 0.04 & 0.08 & 1.00 & 1.41 & 2.95 \\
\hline
\end{tabular}

